\title{
A Humanized Anti-CD22-Onconase Antibody-Drug Conjugate Mediates Highly Potent Destruction of Targeted Tumor Cells
}

\author{
Tobias Weber, ${ }^{1}$ Athanasios Mavratzas, ${ }^{1}$ Stefan Kiesgen, ${ }^{1}$ Stephanie Haase, ${ }^{1}$ \\ Benedikt Bötticher, ${ }^{1}$ Evelyn Exner, ${ }^{1}$ Walter Mier, ${ }^{2}$ Ludger Grosse-Hovest, ${ }^{3}$ Dirk Jäger, ${ }^{1}$ \\ Michaela A. E. Arndt, ${ }^{1,4}$ and Jürgen Krauss ${ }^{1}$ \\ ${ }^{1}$ Department of Medical Oncology, National Center for Tumor Diseases, Heidelberg University Hospital, 69120 Heidelberg, Germany \\ ${ }^{2}$ Department of Nuclear Medicine, Heidelberg University Hospital, 69120 Heidelberg, Germany \\ ${ }^{3}$ Department of Immunology, University of Tübingen, 72076 Tübingen, Germany \\ ${ }^{4}$ Immunotherapy Program, National Center for Tumor Diseases, German Cancer Research Center (DKFZ), \\ 69120 Heidelberg, Germany
}

Correspondence should be addressed to Jürgen Krauss; juergen.krauss@nct-heidelberg.de

Received 10 May 2015; Accepted 1 October 2015

Academic Editor: Nejat K. Egilmez

Copyright (C) 2015 Tobias Weber et al. This is an open access article distributed under the Creative Commons Attribution License, which permits unrestricted use, distribution, and reproduction in any medium, provided the original work is properly cited.

\begin{abstract}
Antibody-drug conjugates (ADCs) have evolved as a new class of potent cancer therapeutics. We here report on the development of ADCs with specificity for the B-cell lineage specific (surface) antigen CD22 being expressed in the majority of hematological malignancies. As targeting moiety a previously generated humanized anti-CD22 single-chain variable fragment (scFv) derivative from the monoclonal antibody RFB4 was reengineered into a humanized IgG1 antibody format (huRFB4). Onconase (ranpirnase), a clinically active pancreatic-type ribonuclease, was employed as cytotoxic payload moiety. Chemical conjugation via thiol-cleavable disulfide linkage retained full enzymatic activity and full binding affinity of the ADC. Development of sophisticated purification procedures using size exclusion and ion exchange chromatography allowed the separation of immunoconjugate species with stoichiometrically defined number of Onconase cargos. A minimum of two Onconase molecules per IgG was required for achieving significant in vitro cytotoxicity towards lymphoma and leukemia cell lines. Antibody-drug conjugates with an Onconase to antibody ratio of $3: 1$ exhibited an $\mathrm{IC}_{50}$ of $0.08 \mathrm{nM}$, corresponding to more than 18,400-fold increased cytotoxicity of the ADC when compared with unconjugated Onconase. These results justify further development of this ADC as a promising first-in-class compound for the treatment of CD22-positive malignancies.
\end{abstract}

\section{Introduction}

The incidence of B-cell neoplasms in Europe has been estimated at approximately 21 per 100,000 [1]. Modern treatment concepts increasingly take phenotype, genotype, and risk factors into consideration. Optimization of conventional cytostatic regimens through addition of tumor-specific antiCD20 monoclonal antibodies (mAbs) or dose intensification followed by autologous/allogeneic stem cell transplantation has significantly improved treatment outcome of B-cell neoplasms over the last years [2].

However, many patients eventually succumb either to treatment-refractory disease or to severe treatment-related side effects $[3,4]$. This necessitates the development of target-directed anticancer therapies with increased antitumor efficacy, yet acceptable systemic toxicity. Antibody-drug conjugates (ADCs) harness the targeting function of monoclonal antibodies towards tumor-associated antigens (TAA) to deliver potent cytotoxic drugs. ADCs have progressed to phase III trials and the first such compounds approved were gemtuzumab ozogamicin and brentuximab vedotin for the treatment of acute myeloid leukemia and relapsed Hodgkin and anaplastic large cell lymphoma, respectively. With only modest complete remission rates of 30\% [5] and unexpectedly severe postapproval toxicity that in part outweighed its clinical benefit [6] gemtuzumab ozogamicin has been withdrawn 
in the US in 2010. More recently trastuzumab emtansine (T-DM1) has been approved for the treatment of metastasized HER2-positive breast cancer [7]. For the treatment of hematologic malignancies several other ADCs, targeting CD79b, CD74, CD33, CD30, CD22, and CD19, are currently in clinical development. Prerequisite for the antitumoral activity of ADCs is sufficient cellular internalization of the compound upon TAA-binding, followed by the intracellular release of the carried payload [8]. The B-cell lineage restricted receptor $\mathrm{CD} 22$, being overexpressed in the majority of $\mathrm{B}$-cell non-Hodgkin lymphomas (B-NHL) [9], as well as in B-cell precursor acute lymphoblastic leukemia (BCP-ALL) [10], is a particularly attractive target for ADC approaches. This is due to the very rapid and sustained internalization of the targeted receptor $[11,12]$ and its absence on hematopoietic stem cells [13]. Inotuzumab ozogamicin (CMC-544), an antiCD22-calicheamicin ADC, has been extensively studied in patients with both indolent and aggressive B-cell NHL as well as acute leukemias [14]. Several phase I and II studies conducted with inotuzumab ozogamicin demonstrated in part highly significant clinical activity across all explored entities. However, in 2013 an ongoing phase III study in patients with aggressive B-NHL was discontinued since an interim analysis of overall survival demonstrated no statistically significant superiority of CMC-544 in combination with rituximab over the comparator arm. The press release reporting on the study termination concluded that "hematologic cancers are a complex group of diseases, with more than 70 different types of lymphomas, leukemias or myelomas that require unique treatment options." Therefore, clinical development of anti-CD22 ADCs with alternative payloads remains of utmost importance. The murine anti-CD22 IgG1 mAb RFB4 and a disulfide antibody fragment derivative, dsFv-RFB4, have been covalently linked to plant toxins or genetically fused to bacterial toxins, respectively [15-19]. From these compounds particularly the recombinant immunotoxin BL22 has produced highly impressive clinical results [20]. However, administration of BL22 was associated with severe adverse effects such as immunogenic reactions and in a few cases development of capillary leak syndrome. As a consequence, a higher affinity antibody fragment derivative for linkage to the bacterial toxin has been developed and the compound (HA22, CAT 8015) exhibited a more favorable toxicity profile, yet similar potent activity as its predecessor in a phase I trial in patients with chemotherapy-resistant hairy cell leukemia [21].

Valuable payload alternatives to bacterial toxins are ribonucleases from the pancreatic ribonuclease (RNase) A superfamily with near absence of immunogenicity [22]. Onconase (ONC, ranpirnase), a $12 \mathrm{kDa}$ basic single-chain protein, originally isolated from oocytes of Rana pipiens [23], kills tumor cells with an $\mathrm{LD}_{50}$ of $10^{-7} \mathrm{M}$ which is comparable to the potency of maytansinoids and auristatins. The antitumor effects of ONC can be ascribed to tRNA- [24, 25], dsRNA- [26], and miRNA-cleavage [26, 27], as well as to transcriptional gene regulation interactions [28]. In phase I/II clinical trials for treatment of various solid tumors and malignant mesothelioma ONC was immunologically well tolerated and displayed acceptable and reversible systemic toxicity [29, 30]. After conjugation to the murine antiCD22 IgG2a-mAb LL2 [31], ONC caused only mild off-target toxicity in lymphoma xenografted mice, and the toxic total cumulative dose (TCD) was reached only at concentrations of $>300 \mathrm{mg} / \mathrm{kg}$ body weight. In comparison, a Pseudomonas exotoxin-LL2 immunoconjugate caused 100\% lethality in mice at a TCD of $7 \mathrm{mg} / \mathrm{kg}$ [32]. Thus, ONC seems to present a promising payload for anti-CD22 immunoconjugates by combining high antitumor potency and low systemic toxicity.

In this study we report on the generation, purification, and in vitro characterization of different ONC-based antiCD22 immunoconjugates. As antibody targeting moiety we reengineered the previously humanized RFB4 scFv [33] into a humanized IgG1. We tested two different chemical conjugation strategies using various crosslinkers for noncleavable and thiol-cleavable linkage and different ONC payload formats. Sophisticated purification procedures were used for obtaining active ADCs with distinct molar drug to antibody ratios (DARs). We show that immuno-RNases were able to kill targeted lymphoma and leukemia cells in a DAR-dependent manner.

\section{Materials and Methods}

2.1. Materials. All tumor cell lines were purchased from ATCC (Manassas, VA, USA). Onconase (ranpirnase) was a kind gift from Kuslima Shogen (Alfacell Corporation, New Jersey, USA).

AhdI and SfiI were obtained from New England Biolabs (Ipswich, USA). The RNase substrate poly-rU was acquired from Amersham Biosciences (Little Chalfont, $\mathrm{UK})$; the fluorogenic substrate 6-FAM-dArUdGdA-BHQ1 (6-Carboxyfluorescein-dArUdGdA-Black-Hole-Quencher1) was from biomers.net (Ulm, Germany). FITC- (fluorescein isothiocyanate-) conjugated secondary antibodies were obtained from Jackson ImmunoResearch (Laboratories, West Grove, PA, USA); the control antibody RFB4 was from Santa Cruz Biotechnology (Dallas, Texas, USA). BenchMark Prestained Protein Ladder, DMEM (Dulbecco's Modified Eagle's Medium), 2-mercaptoethanol, NuPAGE LDS Sample Buffer (4x), Novex HIMark Pre-Stained Protein Standard, Novex Tris-Acetate SDS Running Buffer, and Novex NuPAGE 3-8\% Tris-Acetate Gels were purchased from Life Technologies GmbH (Darmstadt, Germany). RunBlue LDS Sample Buffer, RunBlue Rapid SDS Run Buffer, and RunBlue 12\% SDS Gels were acquired from Expedeon (Harston, UK). FBS (fetal bovine serum), PBS (phosphate buffered saline), penicillin, RPMI-1640 (Roswell Park Memorial Institute) medium, sodium azide, and streptomycin were obtained from Sigma-Aldrich (St. Louis, MO, USA). AlamarBlue, 2-IT (2-iminothiolane), SMCC (succinimidyl 4-(N-maleimidomethyl) cyclohexane-1-carboxylate), SPDP (N-succinimidyl 3-(2-pyridyldithio) propionate), and Spectra Multicolor Broad Range Protein Ladder were procured from Thermo Fisher Scientific (Waltham, MA, USA). APS (ammonium persulfate), coomassie brilliant blue R-250, DMSO (dimethyl sulfoxide), DTT (dithiothreitol), G418 (geneticin disulfate), glycerol, isopropanol, MES (2-(N-morpholino) ethanesulfonic acid), $\mathrm{NaCl}$ (sodium chloride), Rotiphorese Gel 30 acrylamide/bisacrylamide 
solution, SDS (sodium dodecyl sulfate), toluidine blue, Tris-HCl (Tris(hydroxymethyl)aminomethane hydrochloride), and ZelluTrans/Roth dialysis membranes were provided by Carl Roth GmbH (Karlsruhe, Germany). CDM HD (Chemically Defined Medium High Density) serum replacement and the hollow fiber cell culture bioreactor were purchased from FiberCell Systems (Frederick, USA). Amicon Ultra centrifugal filter units, EDTA (ethylenediaminetetraacetic acid, disodium salt dihydrate), and Millex-GV sterile filter units were purchased from Merck KGaA (Darmstadt, Germany). TEMED (N,N,N,N-tetramethylethylenediamine) was obtained from Fluka Biochemika (Buchs, Switzerland). Cell culture plates were purchased from Greiner Bio-One (Kremsmünster, Austria). All columns used for purification were provided by GE Healthcare (Little Chalfont, UK).

2.2. Generation, Production, and Purification of Humanized

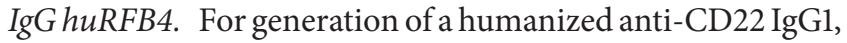
variable domain genes of the previously humanized $\mathrm{scFv}$ SGIII [33] were synthesized (Entelechon GmbH, Bad Abbach, Germany) with splice donor and acceptor signal sequences and cloned into eukaryotic expression vectors containing regulatory elements of the immunoglobulin locus, a human constant heavy $\gamma 1$ chain, and a human constant $\kappa$ chain, respectively. Heavy chain and light chain plasmids of the humanized antibody construct were linearized with $A h d I$ and SfiI, respectively, and transfected into Sp2/0-Ag14 mouse myeloma cells by electroporation $(230 \mathrm{~V}, 975 \mu \mathrm{F})$. Cells were grown by limiting dilution in selective media (DMEM, 10\% FBS, $50 \mu \mathrm{M}$ 2-mercaptoethanol, and $1 \mathrm{mg} / \mathrm{mL}$ G418) for 23 weeks to obtain single-cell clones. Positive clones were identified by flow cytometric analysis and monitored for IgG secretion rates by Dot Blot using a purified $\mathrm{mAb}$ as reference standard. The highest producing clone for huRFB4 IgG was expanded to T-175 flasks, adapted to high glucose DMEM culture media supplemented with 10\% CDM HD serum replacement, and subsequently inoculated into a hollow fiber cell culture bioreactor. IgGs were purified from cell culture supernatants by protein A chromatography using a HiTrap rProtein A FF column and dialyzed against PBS (pH 7.4). Purity was assessed by analytical size exclusion chromatography on a Superdex $20010 / 300$ GL column as $\geq 95 \%$.

2.3. Chemical Conjugation. Intermolecular protein conjugation of ONC and mAb huRFB4 was performed using as heterobifunctional cross-linking agents either succinimidyl 4-( $N$-maleimidomethyl) cyclohexane-1-carboxylate (SMCC) or $\mathrm{N}$-succinimidyl 3-(2-pyridyldithio) propionate (SPDP) for noncleavable and thiol-cleavable linkage, respectively. SMCC and SPDP solutions were freshly prepared in DMSO and diluted 1:10 in PBS (pH 7.4) shortly before use. To generate SMCC-based immunoconjugates purified huRFB4 IgG antibody $(1 \mathrm{mg} / \mathrm{mL})$ was incubated with 40 -fold molar excess of SMCC in PBS (pH 7.4) containing $5 \mathrm{mM}$ EDTA for $30 \mathrm{~min}$ at room temperature. ONC $(2 \mathrm{mg} / \mathrm{mL})$ was simultaneously reduced to des(30-75)-ONC in PBS (pH 7.2) in the presence of $5 \mathrm{mM}$ DTT and $0.2 \mathrm{nM}$ EDTA for $120 \mathrm{~min}$ at $15^{\circ} \mathrm{C}$ [34]. SMCC and DTT were removed by dialysis against PBS ( $\mathrm{pH} 7.4$ ) containing $5 \mathrm{mM}$ EDTA. The maleimide activated antibody was added to a 4.0 -fold molar excess of des(30-75)-ONC and the reaction mixture was incubated for $30 \mathrm{~min}$ at room temperature.

In order to prepare SPDP-based immunoconjugates, purified huRFB4 IgG antibody $(1 \mathrm{mg} / \mathrm{mL})$ was incubated with a 40 -fold molar excess of 2-iminothiolane (2-IT) in PBS ( $\mathrm{pH}$ 8.0) in the presence of $5 \mathrm{mM}$ EDTA for $60 \mathrm{~min}$ at room temperature. ONC $(2 \mathrm{mg} / \mathrm{mL})$ was simultaneously incubated with a 2.0 -fold molar excess of SPDP in PBS (pH 7.4) in the presence of $5 \mathrm{mM}$ EDTA for $60 \mathrm{~min}$ at room temperature. Excess reagents were removed using PD-MiniTrap G-25 columns equilibrated with PBS ( $\mathrm{pH}$ 7.4) containing $5 \mathrm{mM}$ EDTA. Both modified proteins were combined and incubated overnight at $4^{\circ} \mathrm{C}$ for conjugation using a 10 -fold molar excess of pyridyldithiol-activated ONC.

2.4. Purification of ADCs with Distinct Molar Drug to Antibody Ratio. All chromatographic runs were performed at room temperature. The SMCC-based immunoconjugate preparations were subjected to preparative size exclusion chromatography (SEC) on a Superdex 200 10/300 GL column equilibrated and eluted with PBS ( $\mathrm{pH}$ 7.4) at a flow rate of $0.5 \mathrm{~mL} / \mathrm{min}$. Preparative SEC of the SPDP-based immunoconjugate preparations was performed on a HiLoad 16/60 Superdex $200 \mathrm{pg}$ column with a flow rate of $0.3 \mathrm{~mL} / \mathrm{min}$ using $20 \mathrm{mM}$ MES, $50 \mathrm{mM} \mathrm{NaCl}$ at pH 6.0 as elution buffer. Antibody-ONC conjugate populations isolated by SEC were subjected to preparative ion exchange chromatography (IEX) on a Mono-S 5/50 GL column at a flow rate of $1 \mathrm{~mL} / \mathrm{min}$. SPDP immunoconjugates with different ONC-mAb ratios were separated using $20 \mathrm{mM}$ MES ( $\mathrm{pH} 6.0$ ) with a linear $\mathrm{NaCl}$ gradient $(50 \mathrm{mM}-1 \mathrm{M})$ as elution buffer. Specific IEX peak fractions were collected and dialyzed against PBS ( $\mathrm{pH}$ 7.4). Purified protein samples were concentrated using centrifugal filter units, sterile-filtered, and stored at $4^{\circ} \mathrm{C}$. Purity and identity of concentrated immunoconjugates were analyzed by calibrated analytical SEC using a Superdex 200 10/300 GL column.

2.5. Determination of Protein Concentration. Concentrations of homogenously purified proteins were calculated from the absorbance at $280 \mathrm{~nm}$ measured on a NanoDrop ND-1000 spectrophotometer (Thermo Fisher Scientific, Waltham, MA, USA) using the Beer-Lambert law with the molar absorption coefficient $\varepsilon$ and the molecular weight calculated for each individual compound. The calculated $\varepsilon$ value for the unmodified IgG was $203,900 \mathrm{M}^{-1} \cdot \mathrm{cm}^{-1}$, for ONC $10,010 \mathrm{M}^{-1} \cdot \mathrm{cm}^{-1}$, and for the chemically linked immuno-RNases carrying one, two, or three ONC payloads $213,910 \mathrm{M}^{-1} \cdot \mathrm{cm}^{-1}$, $223,920 \mathrm{M}^{-1} \cdot \mathrm{cm}^{-1}$, and $233,930 \mathrm{M}^{-1} \cdot \mathrm{cm}^{-1}$, respectively. The molecular weight was set at $150,000 \mathrm{~g} / \mathrm{mol}$ for the unmodified $\operatorname{IgG}, 11,840 \mathrm{~g} / \mathrm{mol}$ for ONC, and $161,840 \mathrm{~g} / \mathrm{mol}$ (OAR 1:1), $173,680 \mathrm{~g} / \mathrm{mol}$ (OAR 2:1), and 185,520 g/mol (OAR 3:1) for the immunoconjugates. The extinction coefficient and the molecular weight for immunoconjugates with determined sizes of $250-290 \mathrm{kDa}$ were calculated for an ADC with an average payload of 10 RNases and set at $304,000 \mathrm{M}^{-1} \cdot \mathrm{cm}^{-1}$ and $268,400 \mathrm{~g} / \mathrm{mol}$, respectively. To compare antigen binding activity, cytotoxicity, and ribonucleolytic activity of generated 
immunoconjugates, IgG and ONC determined protein concentrations were converted to molarity.

2.6. SDS-PAGE and Densitometry. Protein samples were analyzed by sodium dodecyl sulfate polyacrylamide gel electrophoresis (SDS-PAGE) performed under nonreducing conditions on precast 3-8\% Tris-Acetate gels using Tris-Acetate buffer and under reducing conditions on precast $12 \%$ Bis-Tris gels using Tris-MOPS buffer followed by detection by staining with coomassie brilliant blue. Novex HIMark Pre-Stained Protein Standard and Spectra Multicolor Broad Range Protein Ladder were used as protein standards. Coomassie stained protein bands on reducing SDS-PAGE gels of SPDPbased ADCs were captured on an Epson Perfection V750 Pro scanner (SEIKO Epson Corporation, Nagano, Japan) and analyzed by Photoshop Elements 10 software (Adobe Systems Incorporated, San Jose, USA). After converting to greyscale and applying the invert filter, mean densities of ONC protein bands were determined by histogram analyses.

2.7. Cell Binding Analysis. Specific binding of huRFB4 IgG was determined by flow cytometry using the human CD22positive B-cell lines Daudi, Raji, and Ramos and the human CD22-negative T-cell line Jurkat. Bound huRFB4 IgG and chemically linked immuno-RNases were detected using a FITC-conjugated rabbit antibody specific for the Fc region of human IgG. The mouse monoclonal control antibody RFB4 was detected by staining with an FITC-conjugated goat anti-mouse IgG. Fluorescence recordings were made on a FACSCanto II flow cytometer (BD Biosciences, San Jose, CA, USA) and median fluorescence intensity (MFI) was calculated using the FACSDiva software (BD Biosciences, San Jose, CA, USA). Background fluorescence was determined using cells incubated with FITC-conjugated secondary antibody under the same conditions. Equilibrium-binding curves were determined by incubating $5 \times 10^{5}$ Raji cells in triplicate with serial dilutions of either murine RFB4, huRFB4 IgG, or chemically linked immuno-RNases for $2 \mathrm{~h}$ at room temperature in $100 \mu \mathrm{L}$ PBS-FACS buffer containing $2 \%$ FBS and $0.1 \%$ sodium azide. After two washes with $200 \mu \mathrm{L}$ FACS buffer bound antibodies were detected as described above. Background fluorescence was subtracted from measured median fluorescence and relative affinities were determined according to the Levenberg-Marquardt algorithm for nonlinear regression using GraphPad Prism 5.0 (GraphPad Software, La Jolla, CA, USA).

2.8. Analysis of Ribonucleolytic Activity. Ribonucleolytic activity of SMCC-based immunoconjugates was investigated by zymogram gel electrophoresis as previously described [35]. Briefly, samples were prepared in zymogram loading buffer containing final concentrations of $62.5 \mathrm{mM}$ Tris- $\mathrm{HCl}, \mathrm{pH} 6.8$, $10 \%$ glycerol, and $2.5 \%$ SDS and separated under nonreducing conditions on $12 \%$ polyacrylamide gels containing $0.3 \mathrm{mg} / \mathrm{mL}$ poly-rU in the separating gel as a substrate for ONC. After electrophoresis the gel was washed twice using $10 \mathrm{mM}$ Tris$\mathrm{HCl}, \mathrm{pH} 8.0$, containing $20 \%$ isopropanol to remove SDS, and placed in renaturating buffer containing $100 \mathrm{mM}$ Tris- $\mathrm{HCl}$, $\mathrm{pH} 8.0$ for $12 \mathrm{~h}\left(4^{\circ} \mathrm{C}\right)$. RNase activity was detected by staining with $0.2 \%(\mathrm{w} / \mathrm{v})$ toluidine blue in $10 \mathrm{mM}$ Tris- $\mathrm{HCl}, \mathrm{pH} 8.0$ for $10 \mathrm{~min}$, followed by destaining with $10 \mathrm{mM}$ Tris- $\mathrm{HCl}, \mathrm{pH}$ 8.0, until visualization of the ribonucleolytic activity bands was obtained. BenchMark Prestained Protein was used as protein standard.

Ribonucleolytic activity of SPDP-based immuno-RNases and $\mathrm{ONC}$ was quantified using the fluorogenic substrate 6Carboxyfluorescein-dArUdGdA-Black-Hole-Quencher-1 (6FAM-dArUdGdA-BHQ-1). Increase in fluorescence after cleavage of substrate was monitored over time using an Infinite F200 Pro microplate reader (Tecan Group, Männedorf, Switzerland) with a $485 / 535 \mathrm{~nm}$ (excitation/emission) filter set. Reactions were carried out in black 96-well plates in $100 \mathrm{mM}$ MES-NaOH buffer (pH 6.0) containing $100 \mathrm{mM}$ $\mathrm{NaCl}$ and 6-FAM-dArUdGdA-BHQ-1 $(5 \mathrm{nM})$ at $(25 \pm 2)^{\circ} \mathrm{C}$ in a total reaction volume of $200 \mu \mathrm{L}$ per well. Buffer served as negative control and an excess concentration of RNase A was used as positive control. Values of $k_{\text {cat }} / K_{M}$ were calculated using

$$
\frac{k_{\mathrm{cat}}}{K_{M}}=\frac{(\Delta F / \Delta t)}{\left(F_{\max }-F_{0}\right) \cdot[E]},
$$

where $\Delta F / \Delta t$ represents the initial reaction velocity, $F_{0}$ the initial fluorescence intensity before addition of RNase, $F_{\max }$ the fluorescence intensity after complete cleavage of the substrate by excess RNase A, and $[E]$ the RNase concentration. At least three independent assays were performed.

2.9. Cytotoxicity Assay. Human lymphoma and leukemia cells were maintained in RPMI 1640 supplemented with $10 \%$ fetal bovine serum, $100 \mathrm{U} / \mathrm{mL}$ penicillin, and $100 \mu \mathrm{g} / \mathrm{mL}$ streptomycin. Daudi were seeded at a density of $2 \times$ $10^{4} / 100 \mu \mathrm{L}$, while Nalm 6 and Jurkat were seeded at a density of $1 \times 10^{4} / 100 \mu \mathrm{L}$ into 96 -well flat-bottom plates and incubated with various concentrations of protein or buffer as control at $37^{\circ} \mathrm{C}, 5 \% \mathrm{CO}_{2}$ for $72 \mathrm{~h}$ in a total volume of $110 \mu \mathrm{L}$. In order to determine the viability, cells were incubated with $10 \mu \mathrm{L}$ alamarBlue per well at $37^{\circ} \mathrm{C}, 5 \% \mathrm{CO}_{2}$ for $4 \mathrm{~h}$. Absorbance was measured at $570 \mathrm{~nm}$ (reference: $620 \mathrm{~nm}$ ) using an Infinite F200 Pro microplate reader (Tecan Group, Männedorf, Switzerland). Cell viability was expressed as percentage of viable cells treated with protein related to buffer control. The concentration required to inhibit cell viability by $50 \%$ relative to buffer-treated control cells was defined as $\mathrm{IC}_{50}$ (half maximal inhibitory concentration) and was determined from semilogarithmic plots. At least two independent assays with each assay containing triplicates were performed.

\section{Results}

3.1. Reformatting of Humanized Anti-CD22 huRFB4 scFv into Humanized Anti-CD22 huRFB4 IgG for Subsequent Generation of Chemical Immunoconjugates. We have previously grafted the specificity of the murine anti-CD22 monoclonal antibody (mAb) RFB4 into human $\mathrm{V}_{\mathrm{H}}$ and $\mathrm{V}_{\mathrm{L}}$ frameworks preselected for stability from a human antibody phage display library. The resulting humanized huRFB4 scFv (originally designated SGIII) displayed excellent antigen binding and 
stability properties [33]. To generate a humanized IgG1 derivative ( $m A b$ huRFB4) from the $s c F v$ the variable domain encoding genes of the humanized $V_{L}$ chain and $V_{H}$ chain were cloned into immunoglobulin expression vectors containing a human constant heavy $\gamma 1$ chain and a human constant $\kappa$ chain, respectively. The humanized antibody was produced from stably transfected $\mathrm{Sp} 2 / 0$ mouse myeloma cell lines under serum-free conditions in a hollow-fiber culture system and purified from culture supernatants to homogeneity by protein A chromatography. The purified huRFB4 IgG demonstrated specific binding to the human CD22-positive B-cell lines Daudi, Raji, and Ramos, but no binding to the human CD22-negative T-cell line Jurkat (data not shown). Flow cytometric affinity measurements confirmed that huRFB4 IgG retained the same high apparent affinity of $0.27 \pm 0.02 \mathrm{nM}$ as its murine ancestor mAb RFB4 (Figure 1). Bivalent binding of the humanized IgG increased the apparent binding affinity by 36 -fold when compared to the parental monovalent scFv huRFB4 [33].

3.2. Immunoconjugation of huRFB4 IgG and ONC. For conjugating ONC to huRFB4 IgG we first employed the membrane permeable crosslinker succinimidyl 4 -( $N$-maleimidomethyl) cyclohexane-1-carboxylate (SMCC). ONC contains four disulfide bonds of which C30/C75 is solvent exposed. We therefore reduced ONC under mild conditions and simultaneously modified the $\varepsilon$-amino groups of IgG-lysine residues via the $\mathrm{N}$-hydroxysuccinimide (NHS) ester reactive group of SMCC. The SMCC-modified IgG was reacted with free accessible sulfhydryl groups of des(30-75)-ONC via the maleimide group of SMCC, generating nonreducible thioether bonds. This conjugation approach yielded $41 \%$ nonconjugated IgG $(150 \mathrm{kDa})$ and $22 \%$ multimeric immuno-RNase conjugates $(300 \mathrm{kDa})$ (data not shown). Although reductive unfolding of ONC into a single stable intermediate des(30-75)-ONC has been described $[34,36]$, reduction of the 30-75 disulfide bond in ONC for chemical conjugation has not yet been investigated. To assess if this site of conjugation interferes with the ribonucleolytic activity of ONC the $300 \mathrm{kDa}$ immunoconjugates were subjected to zymography. Although multimeric immunoconjugates were enzymatically active (Figure 2(a)) and retained specific antigen binding (Figure 2(b)) they were not cytotoxic (Figure 2(c)).

Therefore we next used the cleavable $N$-succinimidyl 3-(2-pyridyldithio) propionate (SPDP) crosslinker reacting with amino groups of ONC. Lysine residues of the huRFB4 IgG were modified by Traut's Reagent (2-iminothiolane, 2IT) to provide an additional sulfhydryl group for subsequent immunoconjugation. Preparative size exclusion chromatography (SEC) of the SPDP-immunoconjugate preparations yielded three distinct peaks (Figure 3(a)) corresponding to $17.3 \%$ ADC multimers $(58.6 \mathrm{~mL}), 70.2 \%$ immuno-RNase ADCs $(67.9 \mathrm{~mL})$, and $12.5 \%$ pyridyldithiol-activated ONC excess $(106.4 \mathrm{~mL})$ as confirmed by SDS-PAGE under nonreducing and reducing conditions (Figures $3(\mathrm{~b})$ and $3(\mathrm{c})$ ). Multimerization ( $300 \mathrm{kDa} \mathrm{ADCs})$ was most likely attributed to small amounts of ONC molecules carrying two pyridyldithiol reactive groups, resulting in the cross-linking of two 2-ITmodified IgG molecules. Sizes of immuno-RNase ADCs were

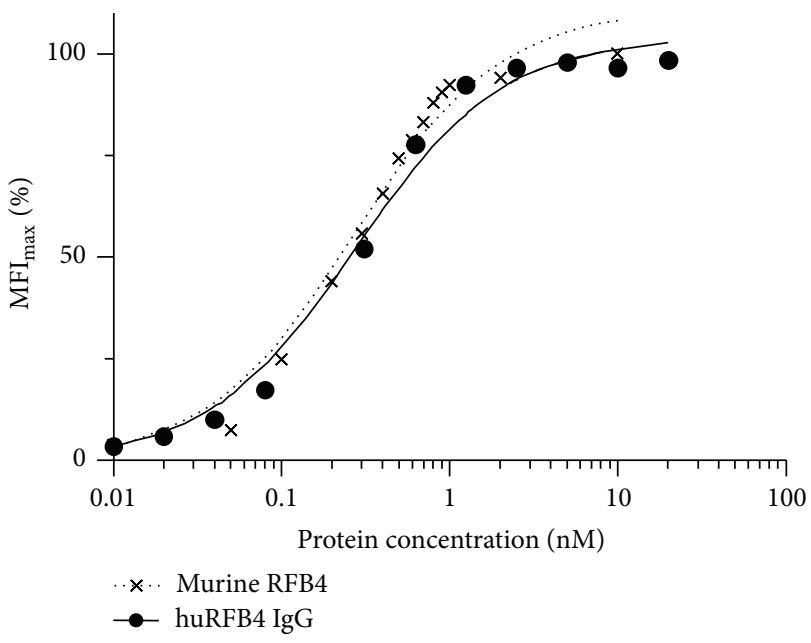

FIGURE 1: Equilibrium-binding curves of murine RFB4 and huRFB4 IgG. Binding activity to CD22-positive Raji cells at indicated concentrations was determined by flow cytometry performing triplicate measurements. Bars represent standard errors (SEs) of mean values. $\mathrm{MFI}_{\max }$ : maximum median fluorescence intensity.

between 162 and $186 \mathrm{kDa}$ (Figure 3(b)), corresponding to ONC to antibody ratios (OARs) between $1: 1$ and $3: 1$.

The small differences of the molecular weights of immuno-RNase ADCs with distinct OARs did not allow a preparative separation by size exclusion chromatography (Figure 3(a)). To separate immuno-RNase ADCs by their number of cytotoxic payloads we thus took advantage of the highly basic nature (pI > 9.5) of ONC [23] and subjected the conjugate pool eluting at $67.9 \mathrm{~mL}$ in SEC (Figure 3(a)) to a polishing step by cation exchange chromatography. By increasing the ionic strength of the elution buffer slowly from 140 to $300 \mathrm{mM} \mathrm{NaCl}$ we were able to separate intact $\mathrm{mAb}$ species with low ONC payloads (Figures 4(a)-4(c)). Immuno-RNase conjugates eluting at $142-174 \mathrm{mM} \mathrm{NaCl}$, 194-221 mM NaCl, and 248-270 in ion exchange chromatography migrated under nonreducing conditions on SDSPAGE with estimated sizes of $162 \mathrm{kDa}, 174 \mathrm{kDa}$, and $186 \mathrm{kDa}$, respectively (Figure $4(\mathrm{a})$ ). The average molecular weights of $162 \mathrm{kDa}, 174 \mathrm{kDa}$, and $186 \mathrm{kDa}$ were confirmed by subsequent calibrated SEC and correspond to distinct immuno-RNase ADCs with OAR of $1: 1,2: 1$, and $3: 1$, respectively. Minor ADC multimer contaminants with sizes $>300 \mathrm{kDa}$ could be separated by SEC (Figure 4(b)). Analysis of immuno-RNase conjugates (defined amount of $1 \mu \mathrm{g}$ each) on reducing SDSPAGE gels showed an OAR depending increase of the staining intensities of ONC protein bands $(12 \mathrm{kDa})$, while staining of the protein bands of the respective IgG heavy and light chains remained unchanged (Figure 4(c)). When compared to the $162 \mathrm{kDa}$ immunoconjugate measured densities of ONC bands increased 1.9-fold for the $174 \mathrm{kDa} \mathrm{ADC}$ and 2.5-fold for the $186 \mathrm{kDa} A D C$, which corresponds very well to the relative amounts of one, two, or three ONC loads per ADC of $6.2 \mathrm{pmol}, 11.5 \mathrm{pmol}$, and $16.2 \mathrm{pmol}$, respectively.

3.3. In Vitro Characterization of SPDP-Based ADCs with Distinct Molar DAR. It has been shown that conjugation 

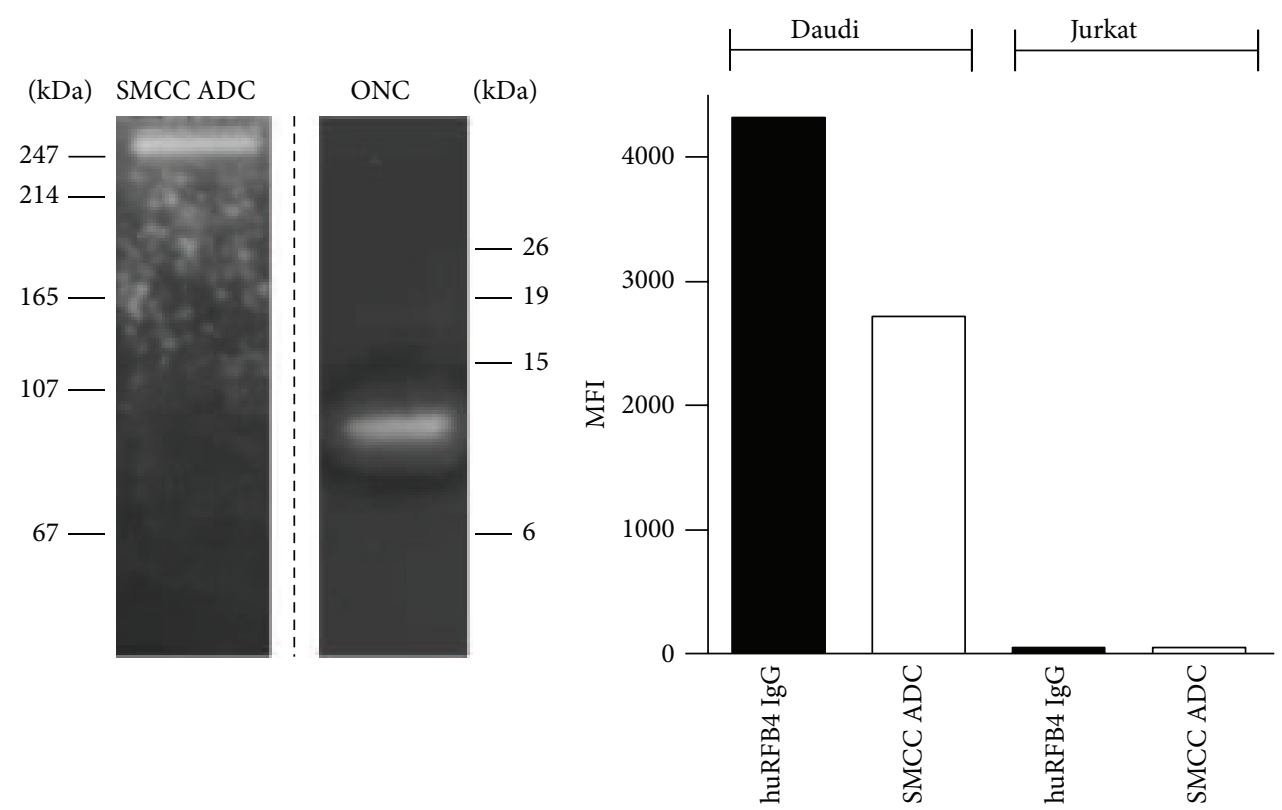

(a)

(b)

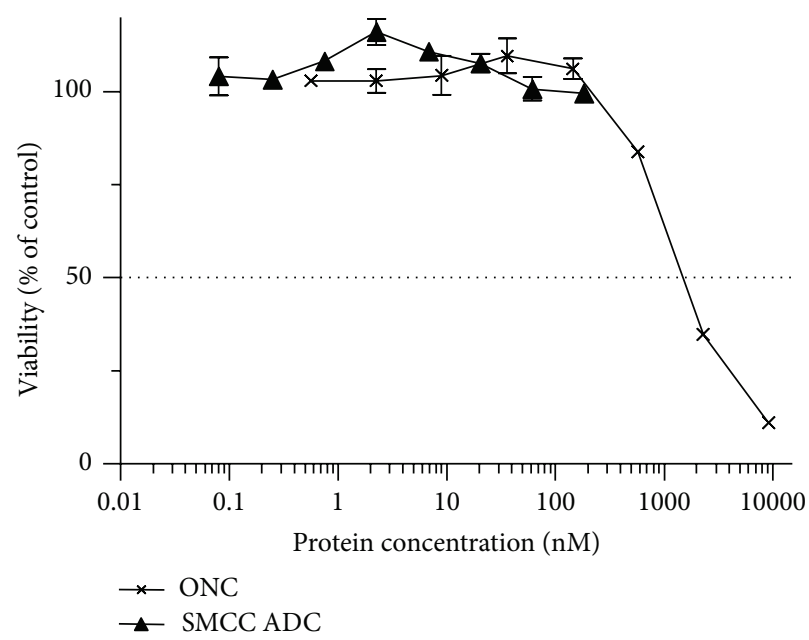

(c)

FIGURE 2: In vitro characterization of SMCC-based immuno-RNase ADCs. (a) In situ RNase activity of the immuno-RNase ADC (1.2 $\mu$ g) and ONC alone $(2.0 \mu \mathrm{g})$ was analyzed by zymogram gel electrophoresis on $12 \%$ SDS polyacrylamide gels containing poly-rU $(0.3 \mathrm{mg} / \mathrm{mL})$ as RNase substrate. Migration distances of molecular weight markers are indicated (kDa). (b) Binding activity of huRFB4 IgG (5 nM) and the immuno-RNase ADC ( $5 \mathrm{nM})$ to CD22-positive Daudi cells and CD22-negative Jurkat cells is shown as median fluorescence intensity (MFI). (c) Cytotoxicity of the immuno-RNase ADC and ONC alone towards CD22-positive Daudi cells in vitro was determined by cell viability assay. Results are expressed relative to buffer-treated control cells. Data depict the mean value \pm SE from one representative experiment performed in triplicate.

procedures requiring pretreatment of ONC with reducing agents such as dithiothreitol (DTT) can diminish ribonucleolytic activity up to $60 \%$ [31]. By employing a conjugation strategy that avoids reduction of ONC we were able to fully maintain the catalytic activity of the ribonuclease in the ADC format (Table 1). As a consequence, the $162 \mathrm{kDa}$ immuno-RNase ADC with an OAR of $1: 1$ showed exactly the same ribonucleolytic activity as ONC alone. The $174 \mathrm{kDa}$ immuno-RNase ADC exhibited 1.9-fold increased ribonucleolytic activity according to two ONC payloads. The $186 \mathrm{kDa}$
immuno-RNase ADC carrying three ONC moieties exhibited a 2.9-fold higher catalytic efficiency than ONC alone. Thus, determination of ribonucleolytic activity additionally confirmed the separation of immuno-RNases with OARs of $1: 1,2: 1$, and $3: 1$. Immunoconjugation had no significant impact on the biological activity of the antibody since antigen binding affinities of the immuno-RNase ADCs $\left(K_{D s}\right.$ 0.4-0.6 nM) were comparable to the affinity of the native huRFB4 IgG (Table 1). Specific antitumor activity of the SPDP-based immunoconjugates with OARs of $1: 1,2: 1$, and 


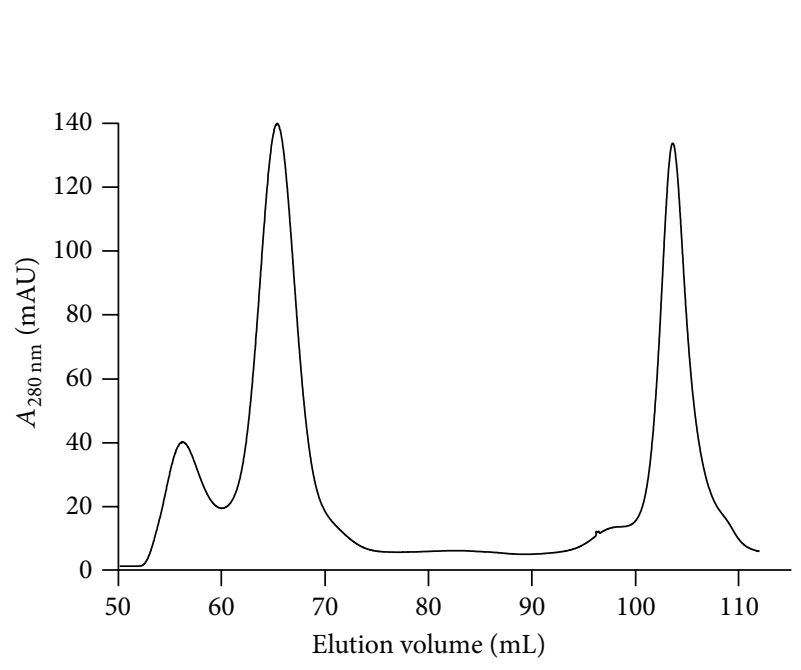

(a)

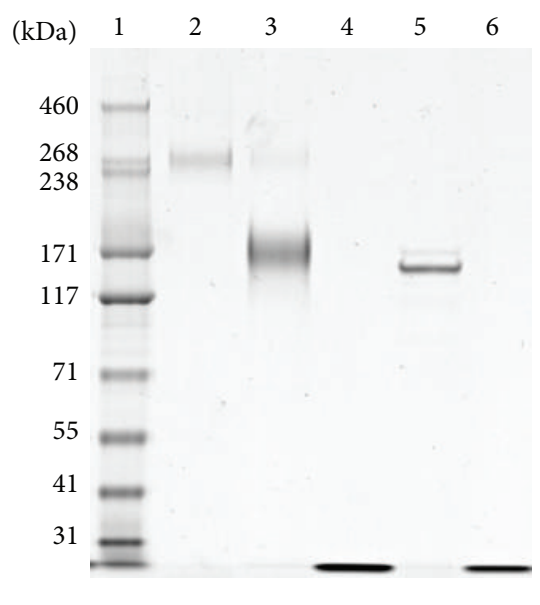

(b)

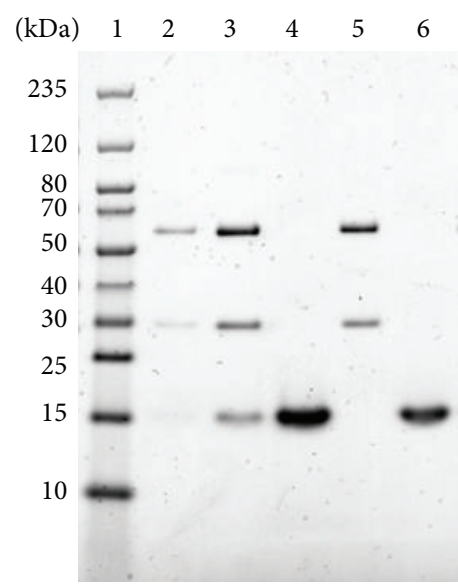

(c)

FIgURE 3: Purification of monomeric SPDP-based ADCs. (a) Size exclusion chromatography of the SPDP-based immunoconjugate preparation on a HiLoad 16/60 Superdex 200 pg column. Eluted column fractions were analyzed by SDS-PAGE under nonreducing (b) and reducing (c) conditions. Lane 1: molecular weight marker; lanes 2-4: column fractions eluting at $58.6 \mathrm{~mL}, 67.9 \mathrm{~mL}$, and $106.4 \mathrm{~mL}$, respectively; lane 5: huRFB4 IgG $(1 \mu \mathrm{g})$; and lane 6: ONC $(1 \mu \mathrm{g})$.

TABLE 1: Binding affinity and ribonucleolytic activity of SPDP-based ADCs.

\begin{tabular}{|c|c|c|c|}
\hline & & Binding affinity ${ }^{a}$ & Ribonucleolytic activity \\
\hline & OAR & $K_{D} \pm \mathrm{SE}(\mathrm{nM})$ & $\begin{array}{c}k_{\mathrm{cat}} / K_{M} \pm \mathrm{SE} \\
\left(10^{3} \mathrm{M}^{-1} \mathrm{~s}^{-1}\right)\end{array}$ \\
\hline ONC & - & NA & $14.1 \pm 0.8$ \\
\hline huRFB4 IgG & - & $0.27 \pm 0.02$ & NA \\
\hline $\begin{array}{l}\text { SPDP-based } \\
162 \mathrm{kDa} \text { ADC }\end{array}$ & $1: 1$ & $0.39 \pm 0.03$ & $14.1 \pm 0.8$ \\
\hline $\begin{array}{l}\text { SPDP-based } \\
174 \mathrm{kDa} \text { ADC }\end{array}$ & $2: 1$ & $0.47 \pm 0.03$ & $26.5 \pm 2.4$ \\
\hline $\begin{array}{l}\text { SPDP-based } \\
186 \mathrm{kDa} \text { ADC }\end{array}$ & $3: 1$ & $0.62 \pm 0.03$ & $40.2 \pm 3.3$ \\
\hline
\end{tabular}

${ }^{a}$ Relative binding affinity $\left(K_{D}\right)$ to CD22-positive Raji cells was calculated from equilibrium-binding curves as determined by flow cytometry performed in triplicate. ${ }^{\mathrm{b}}$ Ribonucleolytic activity $\left(k_{\mathrm{cat}} / K_{M}\right)$ was determined from at least three independent assays. Values are expressed as mean \pm SE. NA: not applicable.
3:1 was tested on human Burkitt's lymphoma Daudi and pre-B acute lymphoblastic leukemia Nalm6 cells in comparison with CD22-negative human acute T-cell leukemia cell line Jurkat. The SPDP-based immuno-RNases meditated a dose-dependent cytotoxicity towards targeted CD22-positive tumor cells (Figures 5(a) and 5(b)) but not towards the CD22-negative leukemia cells (Figure 5(c)). Incubation of Daudi and Nalm6 cells with huRFB4 IgG alone did not result in any cytotoxicity (Figures 5(a) and 5(b)). Notably, a direct correlation between the cytotoxicity of the immunoRNase ADCs and the number of attached cytotoxic payloads became apparent. As anticipated, cytotoxicity successively increased with the number of conjugated payloads (Table 2). In comparison with $\mathrm{ONC}$ alone, displaying $\mathrm{IC}_{50}$ values of $1.5 \mu \mathrm{M}$ on Daudi cells and $0.5 \mu \mathrm{M}$ on Nalm 6 cells, targeted delivery of three ONC moieties per antibody by the most potent $186 \mathrm{kDa} \mathrm{ADC}$ resulted in enhanced cytotoxicity of 18,400-fold on Daudi cells ( $\mathrm{IC}_{50} 80 \mathrm{pM}$ ) and 3,600-fold 
TABLE 2: Dose- and DAR-dependent in vitro cytotoxicity of SPDP-based ADCs.

\begin{tabular}{lcccc}
\hline & OAR & Daudi & Nalm6 & Jurkat \\
& & $\mathrm{IC}_{50} \pm \mathrm{SE}(\mathrm{nM})$ & $\mathrm{IC}_{50} \pm \mathrm{SE}(\mathrm{nM})$ & $\mathrm{IC} \pm \mathrm{SE}(\mathrm{nM})$ \\
\hline ONC & - & $1,469 \pm 44.50$ & $503.2 \pm 21.67$ & $774.5 \pm 99.5$ \\
huRFB4 IgG & - & $>500$ & $>500$ & $>500$ \\
SPDP-based 162 kDa ADC & $1: 1$ & 260.0 & $>284$ & $\mathrm{ND}$ \\
SPDP-based 174 kDa ADC & $2: 1$ & $0.68 \pm 0.30$ & $2.20 \pm 2.07$ & $>390$ \\
SPDP-based 186 kDa ADC & $3: 1$ & $0.08 \pm 0.02$ & $0.14 \pm 0.02$ & $>335$ \\
\hline
\end{tabular}

The concentration required to inhibit cell viability by $50 \%$ relative to buffer-treated control cells $\left(\mathrm{IC}_{50}\right)$ was determined from semilogarithmic plots in which viability as percentage of control was plotted versus the tested protein concentration. $\mathrm{IC}_{50}$ values are expressed as mean $\pm \mathrm{SE}$ and are derived from at least two independent experiments each performed in triplicate. ND: not determined.

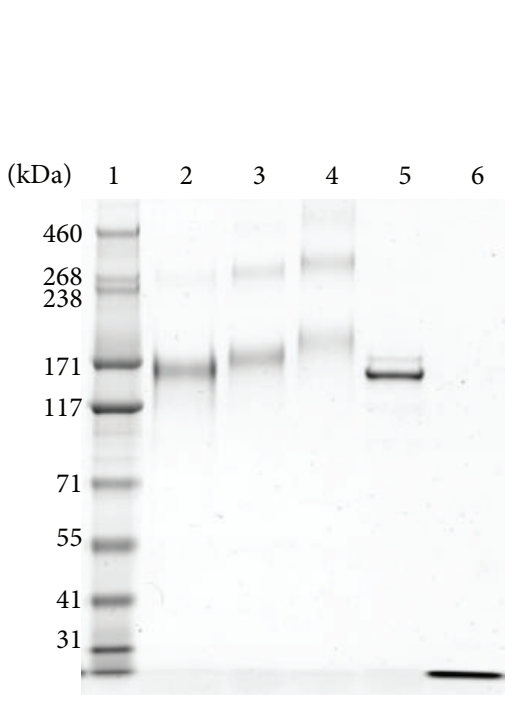

(a)

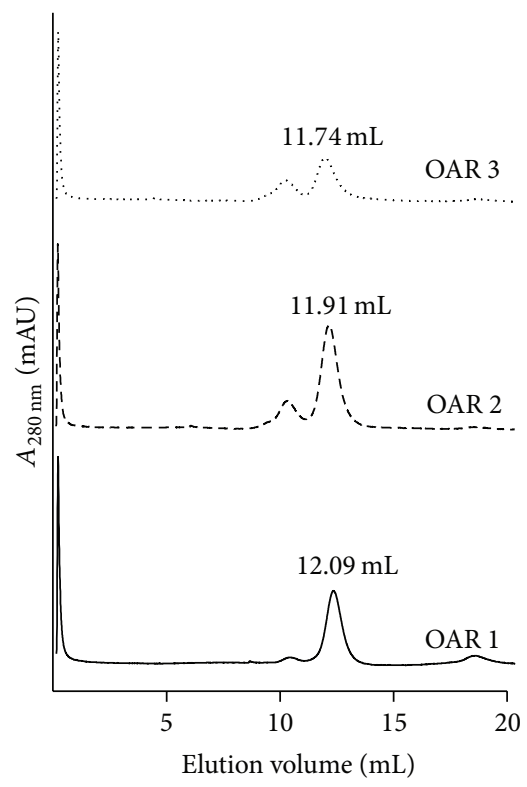

(b)

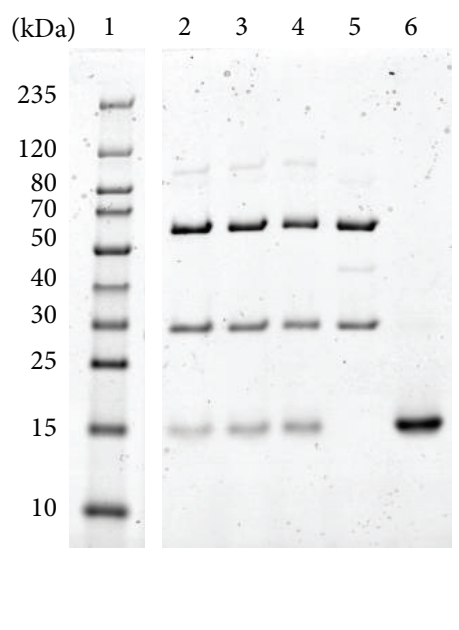

(c)

FIGURE 4: Purification of SPDP-based ADCs with distinct molar DAR. Ion exchange chromatography yielded immuno-RNases with distinct OARs as confirmed by SDS-PAGE under nonreducing (a) and reducing (c) conditions. Lane 1: molecular weight marker; lanes 2-4: ADCs with OARs of 1:1, 2:1, and 3:1 (1 $\mu \mathrm{g}$ each); lane 5: huRFB4 IgG (1 $\mu \mathrm{g})$; lane 6: ONC (1 $\mu \mathrm{g})$. (b) Size exclusion chromatography of IEX-purified immuno-RNases was performed on a Superdex 200 10/300 GL column.

on Nalm6 cells ( $\mathrm{IC}_{50} 140 \mathrm{pM}$ ) (Table 2). SPDP conjugation generated also conjugates with ONC multiplicities eluting in gel filtration chromatography on a calibrated Superdex 200 column at retention times correlating to sizes between 250 and $290 \mathrm{kDa}$ and most likely representing RNase loads of eight to twelve (data not shown). Although this mixture of immunoconjugate species could not be further separated, the effect of higher ONC loading on in vitro potency was evaluated and compared with the immunoconjugates carrying low ONC payloads (Figure 5(d)). At equal molar doses of $10 \mathrm{nM}$, immunoconjugates with one, two, and three ONC payloads reduced the mean viability of Daudi cells by $38 \%, 64 \%$, and $84 \%$, respectively. Although cytotoxic activity correlated with drug loading levels for immunoconjugates with low OAR, immuno-RNase ADCs with higher ONC loadings displayed a significantly decreased cytotoxic activity of only $17 \%$.

\section{Discussion}

Cytotoxic payloads currently under clinical evaluation in ADCs are antimicrotubule agents, DNA minor groove binding agents, and alkylating agents. With biological activities in the $\mathrm{ng} / \mathrm{kg}$ range these compounds represent a major safety challenge both in clinical product manufacturing and in systemic application to cancer patients. The safety and therapeutic index of ADCs significantly depend not only on the reproducibility of exact attachment sites and number of attached payloads but also on the linker technology and conjugate homogeneity. Improvements in linker stability have in fact accelerated the clinical development of new generation $\mathrm{ADCs}$ and resulted in the recent approvals of brentuximab vedotin and ado-trastuzumab emtansine, respectively. Despite implementation of sophisticated downstream 


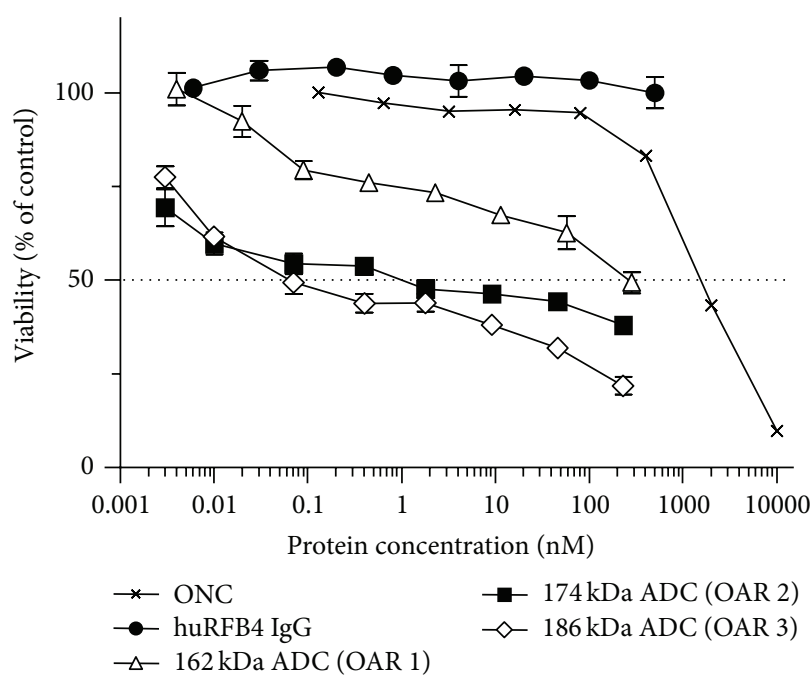

(a)

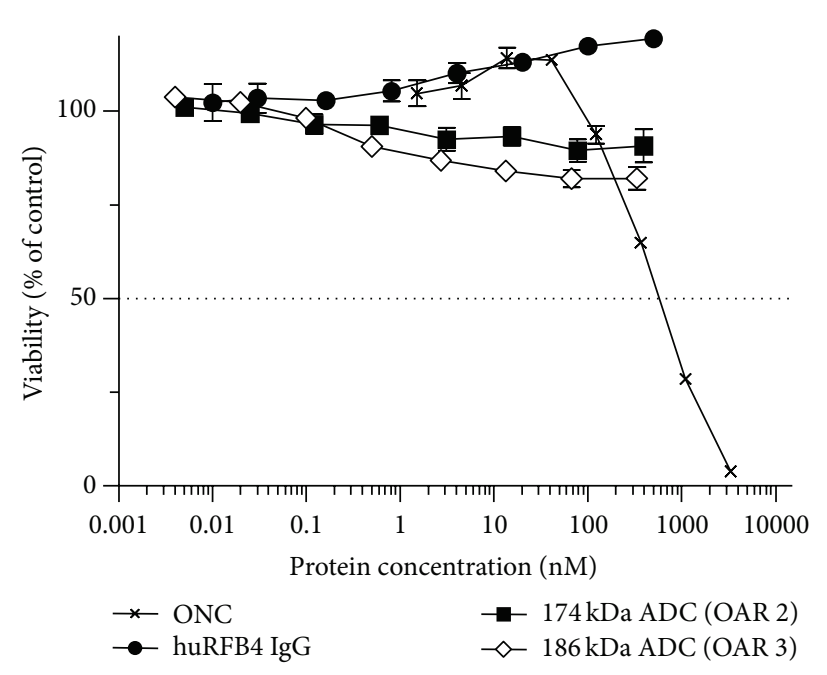

(c)

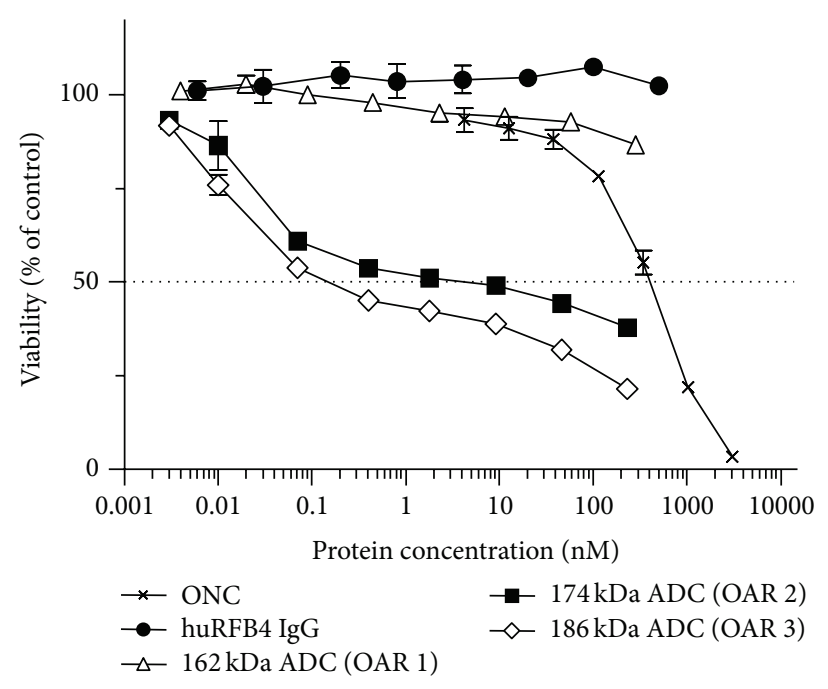

(b)

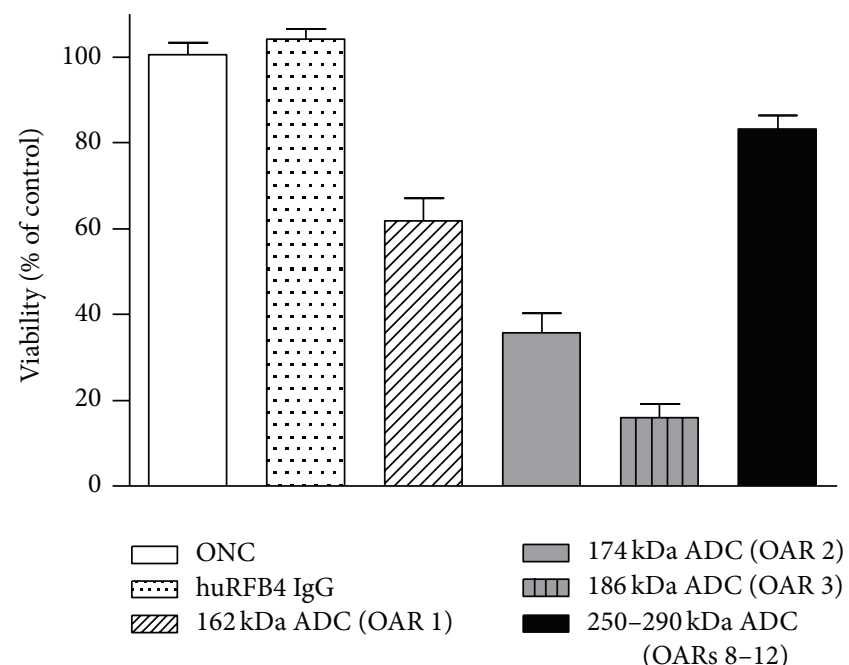

(d)

FIGURE 5: Dose- and DAR-dependent in vitro cytotoxicity of SPDP-based ADCs. CD22-positive Daudi (a), Nalm6 (b), and CD22-negative Jurkat (c) cells were incubated with varying concentrations of SPDP-based ADCs with distinct OARs. ONC and huRFB4 IgG were used as positive and negative control, respectively. Cell viability was determined after $72 \mathrm{~h}$ and is expressed relative to buffer-treated control cells. (d) Cytotoxic activities towards Daudi cells of immunoconjugates with low OAR were compared to antibody-ONC populations with higher ONC loading (OARs 8-12) at equal molar doses of $10 \mathrm{nM}$ each. As immunoconjugate species with eight to twelve ONC payloads could not be further separated, molar calculations for the $250-290 \mathrm{kDa}$ ADC were averaged for a payload of 10 RNases. Data depict the mean value \pm SE from one representative experiment performed in triplicate.

purification protocols conjugation via lysines or cysteines of the antibody results in inherent heterogeneity of the final clinical product with $0-8$ drug payloads per antibody on average. To decrease heterogeneity and achieve uniform drug-loading site-specific drug attachment has recently been achieved by engineered introduction of cysteines [37] or nonnatural amino acids [38]. Employment of these technologies has resulted in ADCs with defined DAR of either two or four payloads per antibody [38-40].

In this study we employed amphibian RNase ONC as effector moiety for creating a novel protein-protein $\mathrm{ADC}$ to target CD22-positive leukemia and lymphoma cells. Prerequisite for the full enzymatic activity of ONC is the formation of pyroglutamate at its $\mathrm{N}$-terminus through hydrogen bonding with $\mathrm{K} 9$ [41, 42]. It is therefore important that crosslinking of ONC to the antibody moiety must not occur via $\mathrm{K} 9$ of the enzyme to preserve the catalytic activity of the ribonuclease. Consequently, we explored two different conjugation strategies for analyzing the impact of the nature of the cross-linking bonds, the stoichiometry, and the efficiency of purification procedures for retaining enzymatic activity and cytotoxicity of the immuno-RNase conjugates. 
Studies on the unfolding pathways of ONC have shown that $\mathrm{ONC}$ reductively unfolds via a single stable intermediate des(30-75)-ONC [34, 36]. It has been further shown that an ONC variant lacking the disulfide bond 30/75 mimics the unfolding intermediate $\operatorname{des}(30-75)-\mathrm{ONC}$ and exhibits comparable cytotoxic properties as wild-type ONC [43]. Mild reduction of the solvent-accessible C30/C75 disulfide bond of ONC was therefore considered a feasible approach for generating active immuno-RNase ADCs. Although amineto-sulfhydryl cross-linking with SMCC resulted in enzymatically active ADCs with sufficient binding activity, the cytotoxic activity was completely abolished. A major drawback of this conjugation approach was the uncontrolled formation of higher molecular weight immunoconjugates with impaired matrix-binding on IEX. Des(30-75)-ONC carrying two sulfhydryl groups per molecule most likely caused multimerization by cross-linking SMCC-modified IgG molecules that resulted in abolishment of cytotoxic activity.

In contrast, formation of SPDP-linked immuno-RNase ADCs via lysine residues seemed primarily to be a result of well-controllable 2-IT and SPDP cross-linking reactions, allowing for a preferential formation of immuno-RNase ADCs with favorably low DARs. High binding affinity to CD22-positive cells, well-preserved ribonucleolytic activity, and high CD22-specific cytotoxicity in vitro indicate no significant alterations of the molecules in critical regions, namely, the CDRs of the IgG, as well as lysine residues K9 and K31 of ONC [41].

Empirical evidence of random conjugation approaches has shown that the number of attached drugs has a significant impact on target antigen binding, systemic clearance, and antitumor efficacy of immunoconjugates [44-48]. Separation of isolated drug load species is at present only possible for dipeptide-linked ADCs, such as anti-CD30 brentuximab vedotin through hydrophobic interaction chromatography (HIC) $[44,49-51]$. We have shown in the present study that IEX matrix-binding of SPDP-linked immuno-RNase ADCs not only allowed for successful purification from nonreacted IgG but also yielded homogenous ADC species with one, two, and three RNase moieties per antibody molecule. Moreover, our data revealed that the number of attached ONC payloads is crucial for achieving significant in vitro cytotoxicity towards CD22-positive lymphoma and leukemia cell lines. In this respect, at least two ONC payloads were required for achieving significant in vitro cytotoxicity and the SPDPlinked immuno-RNase ADC with a DAR of $3: 1$ was most effective. Although reasons for the significantly decreased in vitro potency of immunoconjugates containing eight to twelve ONC payloads per anti-CD22 mAb were not examined in closer detail our data are in line with data from other antibody-drug conjugates showing that higher drug loads increase the risk of reduced cytotoxic activity [47] most likely due to conjugational involvement of lysine residues within the complementarity determining regions (CDRs) of the IgG [48]. In addition, it has been observed in mouse xenograft models that higher drug loading levels (eight drugs per antibody) can cause an accelerated systemic clearance of ADCs which leads to a decreased therapeutic index when compared to conjugates with only four or even only two drugs per antibody [44]. Thus, similar to other optimized non-RNase-based ADCs, it is apparent that the conjugational design of chemically linked immuno-RNases should aim at a low DAR. Another option for successfully obtaining immuno-RNases with stoichiometrically defined number of ONC cargos through employment of the DOCK-ANDLOCK method has recently been reported [52]. Preferably in a head-to-head comparison advantages and disadvantages of both methodologies should be addressed in future studies.

Current clinical and preclinical development strategies for CD22-targeting ADCs and immunotoxins focus on the use of traditional cytotoxic payloads, such as calicheamicins [53], auristatins [54], maytansinoids [55], and truncated Pseudomonas exotoxin [21]. All of these cytotoxic agents have been associated with significant systemic toxicity either due to their off-target release through destabilization of the cross-linking bonds or because of immunogenicity, as in case of Pseudomonas exotoxin. Payload-dependent hematoand hepatotoxicities, ranging from mild, reversible transaminasemia to even fatal venoocclusive disease (VOD), have been reported for the anti-CD22 calicheamicin immunoconjugate inotuzumab ozogamicin (CMC-544) used in clinical phases I-III for the treatment of patients with relapsed/refractory B-cell malignancies [53, 56-58]. Substantial postapproval safety risks attributed to VOD led to the refusal of the marketing authorization in Europe for gemtuzumab ozogamicin $[5,59,60]$ in 2008 and its voluntary withdrawal from the US in 2010. Despite efforts to obtain a maximal ADC stability through introduction of noncleavable thioether bonds or intracellularly cleavable dipeptide bonds preterm payload release with potentially increased toxicity remains a major clinical problem. As with other dipeptidelinked auristatin-based immunoconjugates [61-63], preliminary results of a phase II trial of the anti-CD22-MMAE immunoconjugate pinatuzumab vedotin in combination with rituximab in patients with relapsed/refractory non-Hodgkin lymphoma reported on significant payload-related systemic toxicities including neutropenia and peripheral neuropathy [64]. Since similar toxicities were also common among patients within phase I/II trials of naked auristatin payloads $[65,66]$, deconjugation of the payload from the antibody with systemic release of the neurotoxic microtubule inhibitors can thus be deduced. Payload release from presumably noncleavable thioether bonds has been also demonstrated [67]: during the "thioether fragmentation reaction" the cytotoxic moieties were shown to be transferred to the unpaired C34 cysteine residue of serum albumin. Identification of albumin as a covariate affecting the pharmacokinetics of the recently FDAapproved SMCC-linked anti-HER2 trastuzumab emtansine (T-DM1) [68] might explain at least in part payload-related systemic toxicities observed in late clinical development [69]. Lately, application of self-hydrolyzing maleimide drug linkers has been shown to reduce off-target bone marrow toxicities in rats through enhanced ADC stability [70], which holds promise for future clinical development of such ADCs. While ADCs under current development represent a unique treatment option they create a series of challenges in engineering, chemistry, and safety. Alternative payloads 
with reversible, easily manageable systemic toxicities, yet also high antitumoral efficacy, such as ONC in the present study, represent valuable alternatives.

\section{Conclusion}

In summary, we have developed novel SPDP-linked immunoRNase ADCs with stoichiometrically defined number of cytotoxic ONC payloads for the targeted therapy of CD22 malignancies. We have shown for the first time that the number of attached ONC payloads well correlates with the tumor-specific cytotoxicity of the ADC. Because of their highly specific toxicity towards targeted tumor cells, a fairly well-controllable conjugation and purification procedure, and expected favorable safety and immunogenicity profile we believe that further preclinical development of the 3:1 DAR SPDP-linked immuno-RNase ADC is warranted.

\section{Abbreviations}

ADC: $\quad$ Antibody-drug conjugate

BCP-ALL: B-cell precursor acute lymphoblastic leukemia

B-NHL: B-cell non-Hodgkin lymphoma

CDM HD: Chemically Defined Medium High Density

CDRs: Complementarity determining regions

DAR: Drug to antibody ratio

DMEM: Dulbecco's Modified Eagle's Medium

DMSO: Dimethyl sulfoxide

DTT: Dithiothreitol

EDTA: Ethylenediaminetetraacetic acid

FBS: $\quad$ Fetal bovine serum

FDA: $\quad$ Food and Drug Administration

FITC: $\quad$ Fluorescein isothiocyanate

G418: $\quad$ Geneticin disulfate

HIC: Hydrophobic interaction chromatography

$\mathrm{IC}_{50}$ : Half maximal inhibitory concentration

IEX: Ion exchange chromatography

IgG: Immunoglobulin G

2-IT: 2-Iminothiolane

mAb: $\quad$ Monoclonal antibody

MES: $\quad$ 2-(N-Morpholino)ethanesulfonic acid

MFI: $\quad$ Median fluorescence intensity

MMAE: Monomethyl auristatin E

OAR: Onconase to antibody ratio

ONC: Onconase

RNase: Ribonuclease

PBS: $\quad$ Phosphate buffered saline

RPMI: $\quad$ Roswell Park Memorial Institute

scFv: $\quad$ Single-chain variable fragment

SDS-PAGE: Sodium dodecyl sulfate polyacrylamide gel electrophoresis

SE: $\quad$ Standard error

SEC: $\quad$ Size exclusion chromatography

SMCC: $\quad$ Succinimidyl 4-( $N$-maleimidomethyl) cyclohexane-1-carboxylate

SPDP: $\quad N$-Succinimidyl 3-(2-pyridyldithio) propionate

TAA: Tumor-associated antigen

TCD: Total cumulative dose
TEMED: N,N,N,N-Tetramethylethylenediamine

Tris-HCl: Tris(hydroxymethyl)aminomethane hydrochloride

VOD: Venoocclusive disease.

\section{Conflict of Interests}

The authors declare no conflict of interests.

\section{Authors' Contribution}

Tobias Weber and Athanasios Mavratzas contributed equally to this work.

\section{Acknowledgments}

This research was supported by the Deutsche Krebshilfe. Stefan Kiesgen received a scholarship from the Helmholtz Alliance for Immunotherapy (HAIT).

\section{References}

[1] M. Sant, C. Allemani, C. Tereanu et al., "Incidence of hematologic malignancies in Europe by morphologic subtype: results of the HAEMACARE project," Blood, vol. 116, no. 19, pp. 37243734, 2010.

[2] C.-H. Pui and W. E. Evans, "Treatment of acute lymphoblastic leukemia," The New England Journal of Medicine, vol. 354, no. 2, pp. 166-178, 2006.

[3] B. Coiffier, E. Lepage, J. Brière et al., "CHOP chemotherapy plus rituximab compared with chop alone in elderly patients with diffuse large-B-cell lymphoma," The New England Journal of Medicine, vol. 346, no. 4, pp. 235-242, 2002.

[4] B. T. Hennessy, E. O. Hanrahan, and P. A. Daly, "Non-Hodgkin lymphoma: an update," The Lancet Oncology, vol. 5, no. 6, pp. 341-353, 2004.

[5] E. L. Sievers, R. A. Larson, E. A. Stadtmauer et al., "Efficacy and safety of gemtuzumab ozogamicin in patients with CD33positive acute myeloid leukemia in first relapse," Journal of Clinical Oncology, vol. 19, no. 13, pp. 3244-3254, 2001.

[6] S. Petersdorf, K. Kopecky, R. K. Stuart et al., "Preliminary results of southwest oncology group study s0106: an international intergroup phase 3 randomized trial comparing the addition of gemtuzumab ozogamicin to standard induction therapy versus standard induction therapy followed by a second randomization to post-consolidation gemtuzumab ozogamicin versus no additional therapy for previously untreated acute myeloid leukemia," Blood, vol. 114, p. 790, 2009, ASH Annual Meeting Abstracts.

[7] J. M. Lambert and R. V. J. Chari, "Ado-trastuzumab emtansine (T-DM1): an antibody-drug conjugate (ADC) for HER2positive breast cancer," Journal of Medicinal Chemistry, vol. 57, no. 16, pp. 6949-6964, 2014.

[8] G. R. Braslawsky, K. Kadow, J. Knipe et al., "Adriamycin(hydrazone)-antibody conjugates require internalization and intracellular acid hydrolysis for antitumor activity," Cancer Immunology Immunotherapy, vol. 33, no. 6, pp. 367-374, 1991.

[9] D. Y. Mason, H. Stein, J. Gerdes et al., "Value of monoclonal anti-CD22 (p135) antibodies for the detection of normal and neoplastic B lymphoid cells," Blood, vol. 69, no. 3, pp. 836-840, 1987. 
[10] S. Gudowius, K. Recker, H.-J. Laws et al., "Identification of candidate target antigens for antibody-based immunotherapy in childhood B-cell precursor ALL," Klinische Padiatrie, vol. 218, no. 6, pp. 327-333, 2006.

[11] B. John, B. R. Herrin, C. Raman et al., “The B cell coreceptor CD22 associates with AP50, a clathrin-coated pit adapter protein, via tyrosine-dependent interaction," Journal of Immunology, vol. 170, no. 7, pp. 3534-3543, 2003.

[12] H. Tateno, H. Li, M. J. Schur et al., "Distinct endocytic mechanisms of CD22 (Siglec-2) and Siglec-F reflect roles in cell signaling and innate immunity," Molecular and Cellular Biology, vol. 27, no. 16, pp. 5699-5710, 2007.

[13] L. W. M. M. Terstappen, S. Johnsen, I. M. J. Segers-Nolten, and M. R. Loken, "Identification and characterization of plasma cells in normal human bone marrow by high-resolution flow cytometry," Blood, vol. 76, no. 9, pp. 1739-1747, 1990.

[14] L. Sullivan-Chang, R. T. O’Donnell, and J. M. Tuscano, “Targeting CD22 in B-cell malignancies: current status and clinical outlook," BioDrugs, vol. 27, no. 4, pp. 293-304, 2013.

[15] E. Mansfield, I. Pastan, and D. J. FitzGerald, "Characterization of RFB4-Pseudomonas exotoxin A immunotoxins targeted to CD22 on B-cell malignancies," Bioconjugate Chemistry, vol. 7, no. 5, pp. 557-563, 1996.

[16] E. A. Sausville, D. Headlee, M. Stetler-Stevenson et al., "Continuous infusion of the anti-CD22 immunotoxin IgG-RFB4SMPT-dgA in patients with B-cell lymphoma: a phase I study," Blood, vol. 85, no. 12, pp. 3457-3465, 1995.

[17] R. J. Kreitman, D. R. Squires, M. Stetler-Stevenson et al., "Phase I trial of recombinant immunotoxin RFB4(dsFv)-PE38 (BL22) in patients with B-cell malignancies," Journal of Clinical Oncology, vol. 23, no. 27, pp. 6719-6729, 2005.

[18] R. J. Kreitman, M. Stetler-Stevenson, I. Margulies et al., "Phase II trial of recombinant immunotoxin RFB4(dsFv)-PE38 (BL22) in patients with hairy cell leukemia," Journal of Clinical Oncology, vol. 27, no. 18, pp. 2983-2990, 2009.

[19] R. J. Kreitman, W. H. Wilson, K. Bergeron et al., "Efficacy of the anti-CD22 recombinant immunotoxin BL22 in chemotherapyresistant hairy-cell leukemia," The New England Journal of Medicine, vol. 345, no. 4, pp. 241-247, 2001.

[20] R. A. Messmann, E. S. Vitetta, D. Headlee et al., "A phase I study of combination therapy with immunotoxins IgG-HD37deglycosylated ricin A chain (dgA) and IgG-RFB4-dgA (Combotox) in patients with refractory $\mathrm{CD} 19(+), \mathrm{CD} 22(+) \mathrm{B}$ cell lymphoma," Clinical Cancer Research, vol. 6, no. 4, pp. 13021313, 2000.

[21] R. J. Kreitman, M. S. Tallman, T. Robak et al., "Phase I trial of anti-CD22 recombinant immunotoxin moxetumomab pasudotox (CAT-8015 or HA22) in patients with hairy cell leukemia," Journal of Clinical Oncology, vol. 30, no. 15, pp. 18221828, 2012.

[22] J. Krauss, M. A. E. Arndt, B. K. Vu, D. L. Newton, S. Seeber, and S. M. Rybak, "Efficient killing of $\mathrm{CD} 22^{+}$tumor cells by a humanized diabody-RNase fusion protein," Biochemical and Biophysical Research Communications, vol. 331, no. 2, pp. 595602, 2005.

[23] W. Ardelt, S. M. Mikulski, and K. Shogen, "Amino acid sequence of an anti-tumor protein from Rana pipiens oocytes and early embryos. Homology to pancreatic ribonucleases," The Journal of Biological Chemistry, vol. 266, no. 1, pp. 245-251, 1991.

[24] M. S. Iordanov, O. P. Ryabinina, J. Wong et al., "Molecular determinants of apoptosis induced by the cytotoxic ribonuclease onconase: evidence for cytotoxic mechanisms different from inhibition of protein synthesis," Cancer Research, vol. 60, no. 7, pp. 1983-1994, 2000.

[25] S. K. Saxena, R. Sirdeshmukh, W. Ardelt, S. M. Mikulski, K. Shogen, and R. J. Youle, "Entry into cells and selective degradation of tRNAs by a cytotoxic member of the RNase A family," Journal of Biological Chemistry, vol. 277, no. 17, pp. 15142-15146, 2002.

[26] A. Saxena, S. K. Saxena, and K. Shogen, "Effect of onconase on double-stranded RNA in vitro," Anticancer Research, vol. 29, no. 4, pp. 1067-1072, 2009.

[27] C. M. Goparaju, J. D. Blasberg, S. Volinia et al., "Onconase mediated NFK $\beta$ downregulation in malignant pleural mesothelioma," Oncogene, vol. 30, no. 24, pp. 2767-2777, 2011.

[28] D. A. Altomare, S. M. Rybak, J. Pei et al., "Onconase responsive genes in human mesothelioma cells: implications for an RNA damaging therapeutic agent," BMC Cancer, vol. 10, article 34, 2010.

[29] S. Mikulski, A. Grossman, P. Carter, K. Shogen, and J. Costanzi, "Phase-I human clinical-trial of onconase(r) (p-30 protein) administered intravenously on a weekly schedule in cancerpatients with solid tumors," International Journal of Oncology, vol. 3, no. 1, pp. 57-64, 1993.

[30] S. M. Mikulski, J. J. Costanzi, N. J. Vogelzang et al., "Phase II trial of a single weekly intravenous dose of ranpirnase in patients with unresectable malignant mesothelioma," Journal of Clinical Oncology, vol. 20, no. 1, pp. 274-281, 2002.

[31] D. L. Newton, H. J. Hansen, S. M. Mikulski, D. M. Goldenberg, and S. M. Rybak, "Potent and specific antitumor effects of an anti-CD22-targeted cytotoxic ribonuclease: potential for the treatment of non-Hodgkin lymphoma," Blood, vol. 97, no. 2, pp. 528-535, 2001.

[32] R. J. Kreitman, H. J. Hansen, A. L. Jones, D. J. P. FitzGerald, D. M. Goldenberg, and I. Pastan, "Pseudomonas exotoxin-based immunotoxins containing the antibody LL2 or LL2-Fab' induce regression of subcutaneous human B-cell lymphoma in mice," Cancer Research, vol. 53, no. 4, pp. 819-825, 1993.

[33] J. Krauss, M. A. E. Arndt, A. C. R. Martin, H. Liu, and S. M. Rybak, "Specificity grafting of human antibody frameworks selected from a phage display library: generation of a highly stable humanized anti-CD22 single-chain Fv fragment," Protein Engineering, vol. 16, no. 10, pp. 753-759, 2003.

[34] M. Narayan, G. Xu, D. R. Ripoll et al., "Dissimilarity in the reductive unfolding pathways of two ribonuclease homologues," Journal of Molecular Biology, vol. 338, no. 4, pp. 795-809, 2004.

[35] J. Krauss, E. Exner, A. Mavratzas, S. Seeber, and M. A. Arndt, "High-level production of a humanized immunoRNase fusion protein from stably transfected myeloma cells," in Therapeutic Antibodies, vol. 525 of Methods in Molecular Biology, pp. 471490, Springer, Berlin, Germany, 2009.

[36] G. Xu, M. Narayan, E. Welker, and H. A. Scheraga, "A novel method to determine thermal transition curves of disulfidecontaining proteins and their structured folding intermediates," Biochemical and Biophysical Research Communications, vol. 311, no. 2, pp. 514-517, 2003.

[37] J. R. Junutula, H. Raab, S. Clark et al., "Site-specific conjugation of a cytotoxic drug to an antibody improves the therapeutic index," Nature Biotechnology, vol. 26, no. 8, pp. 925-932, 2008.

[38] J. Y. Axup, K. M. Bajjuri, M. Ritland et al., "Synthesis of site-specific antibody-drug conjugates using unnatural amino acids," Proceedings of the National Academy of Sciences of the United States of America, vol. 109, no. 40, pp. 16101-16106, 2012. 
[39] J. R. Junutula, K. M. Flagella, R. A. Graham et al., "Engineered thio-trastuzumab-DM1 conjugate with an improved therapeutic index to target human epidermal growth factor receptor 2positive breast cancer," Clinical Cancer Research, vol. 16, no. 19, pp. 4769-4778, 2010.

[40] T. Hofer, L. R. Skeffington, C. M. Chapman, and C. Rader, "Molecularly defined antibody conjugation through a selenocysteine interface," Biochemistry, vol. 48, no. 50, pp. 1204712057, 2009.

[41] Y.-D. Liao, S.-C. Wang, Y.-J. Leu et al., "The structural integrity exerted by N-terminal pyroglutamate is crucial for the cytotoxicity of frog ribonuclease from Rana pipiens," Nucleic Acids Research, vol. 31, no. 18, pp. 5247-5255, 2003.

[42] J. E. Lee, E. Bae, C. A. Bingman, G. N. Phillips Jr., and R. T. Raines, "Structural basis for catalysis by onconase," Journal of Molecular Biology, vol. 375, no. 1, pp. 165-177, 2008.

[43] G. Torrent, A. Benito, J. Castro, M. Ribó, and M. Vilanova, "Contribution of the C30/C75 disulfide bond to the biological properties of onconase," Biological Chemistry, vol. 389, no. 8, pp. 1127-1136, 2008.

[44] K. J. Hamblett, P. D. Senter, D. F. Chace et al., "Effects of drug loading on the antitumor activity of a monoclonal antibody drug conjugate," Clinical Cancer Research, vol. 10, no. 20, pp. 7063-7070, 2004.

[45] C. F. McDonagh, E. Turcott, L. Westendorf et al., "Engineered antibody-drug conjugates with defined sites and stoichiometries of drug attachment," Protein Engineering, Design \& Selection, vol. 19, no. 7, pp. 299-307, 2006.

[46] R. J. Sanderson, M. A. Hering, S. F. James et al., "In vivo druglinker stability of an anti-CD30 dipeptide-linked auristatin immunoconjugate," Clinical Cancer Research, vol. 11, no. 2, pp. 843-852, 2005.

[47] R. V. J. Chari, B. A. Martell, J. L. Gross et al., "Immunoconjugates containing novel maytansinoids: promising anticancer drugs," Cancer Research, vol. 52, no. 1, pp. 127-131, 1992.

[48] R. A. Firestone, D. Willner, S. J. Hofstead et al., "Synthesis and antitumor activity of the immunoconjugate BR96-Dox," Journal of Controlled Release, vol. 39, no. 2-3, pp. 251-259, 1996.

[49] M. M. C. Sun, K. S. Beam, C. G. Cerveny et al., "Reductionalkylation strategies for the modification of specific monoclonal antibody disulfides," Bioconjugate Chemistry, vol. 16, no. 5, pp. 1282-1290, 2005.

[50] C. A. Boswell, E. E. Mundo, C. Zhang et al., "Impact of drug conjugation on pharmacokinetics and tissue distribution of anti-STEAP1 antibody-drug conjugates in rats," Bioconjugate Chemistry, vol. 22, no. 10, pp. 1994-2004, 2011.

[51] Y. T. Adem, K. A. Schwarz, E. Duenas, T. W. Patapoff, W. J. Galush, and O. Esue, "Auristatin antibody drug conjugate physical instability and the role of drug payload," Bioconjugate Chemistry, vol. 25, no. 4, pp. 656-664, 2014.

[52] D. Liu, T. M. Cardillo, Y. Wang, E. A. Rossi, D. M. Goldenberg, and C.-H. Chang, "Trop-2-targeting tetrakis-ranpirnase has potent antitumor activity against triple-negative breast cancer," Molecular Cancer, vol. 13, article 53, 2014.

[53] A. Advani, B. Coiffier, M. S. Czuczman et al., "Safety, pharmacokinetics, and preliminary clinical activity of inotuzumab ozogamicin, a novel immunoconjugate for the treatment of B-cell non-Hodgkin's lymphoma: results of a phase I study," Journal of Clinical Oncology, vol. 28, no. 12, pp. 2085-2093, 2010.
[54] J.-P. Stephan, P. Chan, C. Lee et al., "Anti-CD22-MCC-DM1 and MC-MMAF conjugates: impact of assay format on pharmacokinetic parameters determination," Bioconjugate Chemistry, vol. 19, no. 8, pp. 1673-1683, 2008.

[55] A. G. Polson, M. Williams, A. M. Gray et al., "Anti-CD22-MCCDM1: an antibody-drug conjugate with a stable linker for the treatment of non-Hodgkin's lymphoma," Leukemia, vol. 24, no. 9, pp. 1566-1573, 2010.

[56] L. Fayad, F. Offner, M. R. Smith et al., "Safety and clinical activity of a combination therapy comprising two antibody-based targeting agents for the treatment of non-hodgkin lymphoma: results of a phase I/II study evaluating the immunoconjugate inotuzumab ozogamicin with rituximab," Journal of Clinical Oncology, vol. 31, no. 5, pp. 573-583, 2013.

[57] H. Kantarjian, D. Thomas, J. Jorgensen et al., "Inotuzumab ozogamicin, an anti-CD22-calecheamicin conjugate, for refractory and relapsed acute lymphocytic leukaemia: a phase 2 study," The Lancet Oncology, vol. 13, no. 4, pp. 403-411, 2012.

[58] N. H. Dang, M. Ogura, S. Castaigne et al., "Randomized, phase 3 trial of inotuzumab ozogamicin plus rituximab (R-InO) versus chemotherapy for relapsed/refractory aggressive B-cell nonHodgkin lymphoma (B-NHL)," Journal of Clinical Oncology, vol. 32, no. 5, supplement, abstract 8529, 2014.

[59] R. A. Larson, E. L. Sievers, E. A. Stadtmauer et al., "Final report of the efficacy and safety of gemtuzumab ozogamicin (Mylotarg) in patients with CD33-positive acute myeloid leukemia in first recurrence," Cancer, vol. 104, no. 7, pp. 14421452, 2005.

[60] C. Nabhan, L. Rundhaugen, M. Jatoi et al., "Gemtuzumab ozogamicin (Mylotarg) is infrequently associated with sinusoidal obstructive syndrome/veno-occlusive disease," Annals of Oncology, vol. 15, no. 8, pp. 1231-1236, 2004.

[61] A. Younes, A. K. Gopal, S. E. Smith et al., "Results of a pivotal phase II study of brentuximab vedotin for patients with relapsed or refractory Hodgkin's lymphoma," Journal of Clinical Oncology, vol. 30, no. 18, pp. 2183-2189, 2012.

[62] D. P. Petrylak, D. C. Smith, L. J. Appleman et al., "A phase II trial of prostate-specific membrane antigen antibody drug conjugate (PSMA ADC) in taxane-refractory metastatic castrationresistant prostate cancer (mCRPC)," Journal of Clinical Oncology, vol. 32, supplement 4, abstract 83, 2014.

[63] J. Bendell, M. Saleh, A. A. N. Rose et al., "Phase I/II study of the antibody-drug conjugate glembatumumab vedotin in patients with locally advanced or metastatic breast cancer," Journal of Clinical Oncology, vol. 32, no. 32, pp. 3619-3625, 2014.

[64] F. Morschhauser, I. Flinn, R. H. Advani et al., "Preliminary results of a phase II randomized study (ROMULUS) of polatuzumab vedotin $(\mathrm{PoV})$ or pinatuzumab vedotin $(\mathrm{PiV})$ plus rituximab (RTX) in patients (Pts) with relapsed/refractory (R/R) non-Hodgkin lymphoma (NHL)," Journal of Clinical Oncology, vol. 32, no. 15, supplement, abstract 8519, 2014, 2014 ASCO Annual Meeting Abstracts.

[65] E. A. Perez, D. W. Hillman, P. A. Fishkin et al., "Phase II trial of dolastatin-10 in patients with advanced breast cancer," Investigational New Drugs, vol. 23, no. 3, pp. 257-261, 2005.

[66] K. Tamura, K. Nakagawa, T. Kurata et al., "Phase I study of TZT1027, a novel synthetic dolastatin 10 derivative and inhibitor of tubulin polymerization, which was administered to patients with advanced solid tumors on days 1 and 8 in 3-week courses," Cancer Chemotherapy and Pharmacology, vol. 60, no. 2, pp. 285293, 2007. 
[67] S. C. Alley, D. R. Benjamin, S. C. Jeffrey et al., "Contribution of linker stability to the activities of anticancer immunoconjugates," Bioconjugate Chemistry, vol. 19, no. 3, pp. 759-765, 2008.

[68] M. Gupta, P. M. Lorusso, B. Wang et al., "Clinical implications of pathophysiological and demographic covariates on the population pharmacokinetics of trastuzumab emtansine, a HER2-targeted antibody-drug conjugate, in patients with HER2-positive metastatic breast cancer," The Journal of Clinical Pharmacology, vol. 52, no. 5, pp. 691-703, 2012.

[69] S. Verma, D. Miles, L. Gianni et al., "Trastuzumab emtansine for HER2-positive advanced breast cancer," The New England Journal of Medicine, vol. 367, no. 19, pp. 1783-1791, 2012.

[70] R. P. Lyon, J. R. Setter, T. D. Bovee et al., "Self-hydrolyzing maleimides improve the stability and pharmacological properties of antibody-drug conjugates," Nature Biotechnology, vol. 32, no. 10, pp. 1059-1062, 2014. 


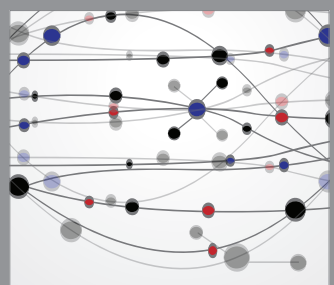

The Scientific World Journal
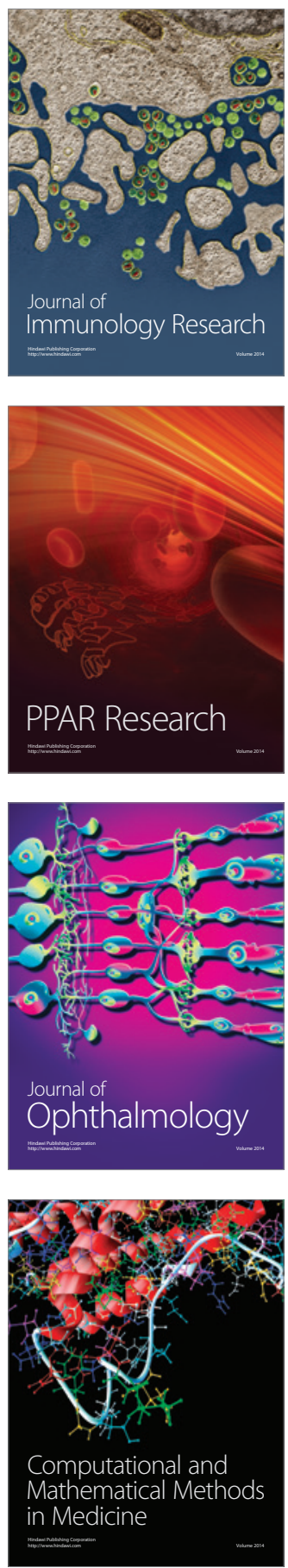

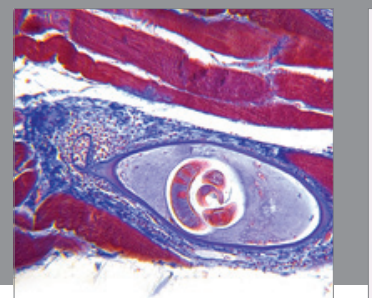

Gastroenterology

Research and Practice
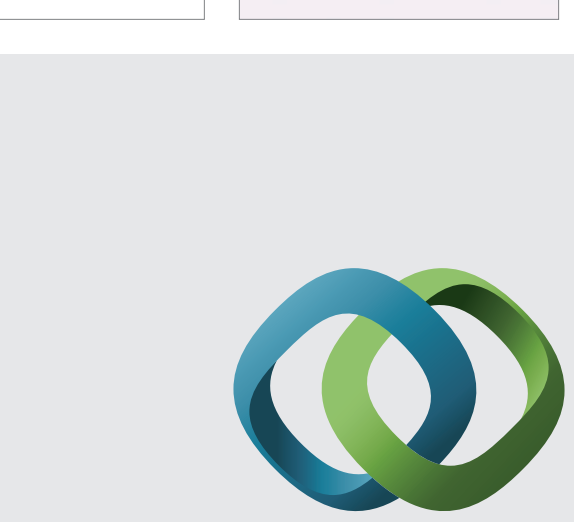

\section{Hindawi}

Submit your manuscripts at

http://www.hindawi.com
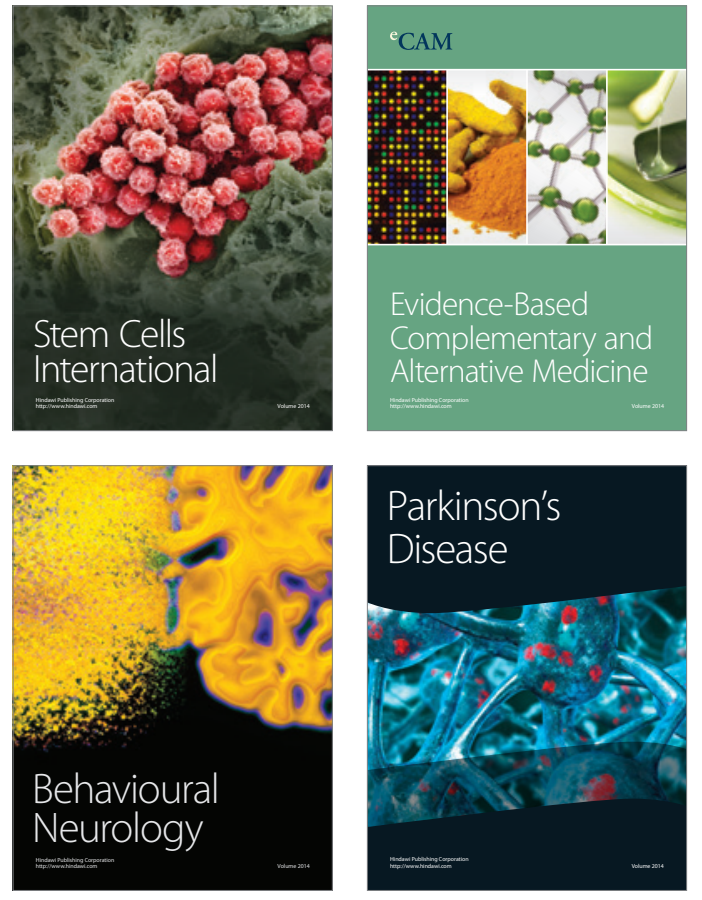
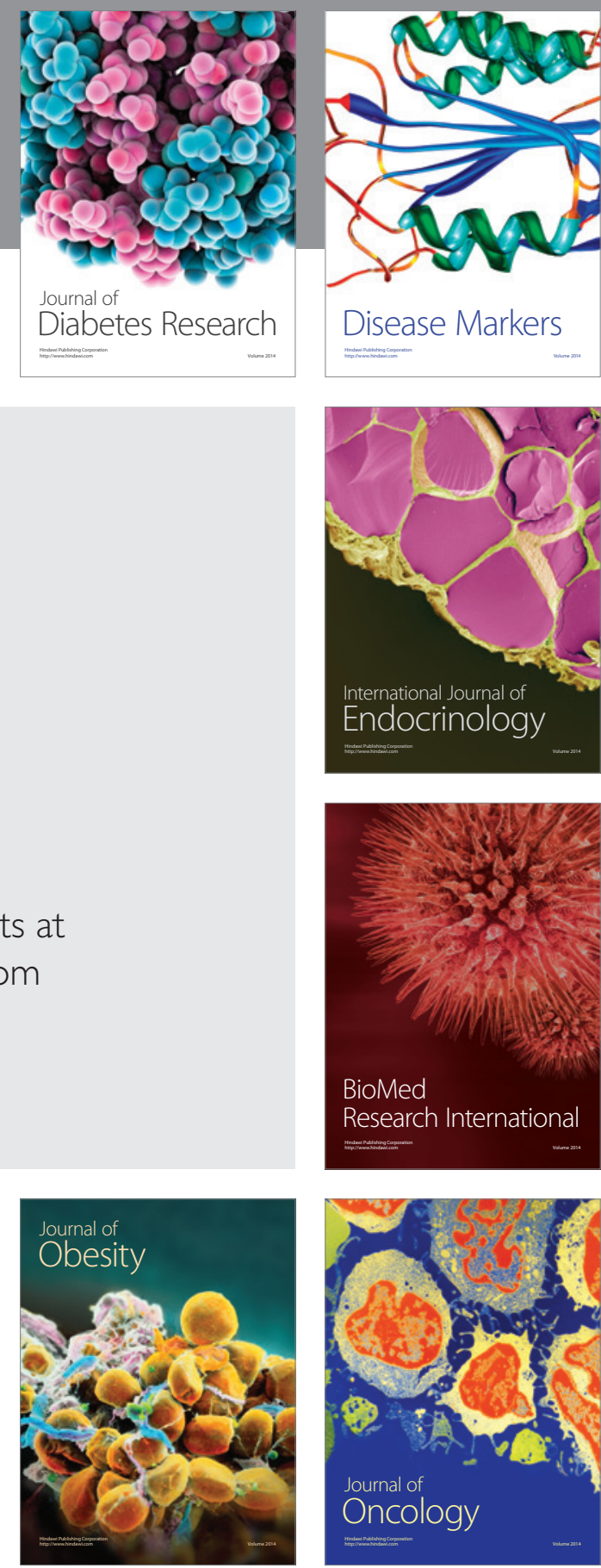

Disease Markers
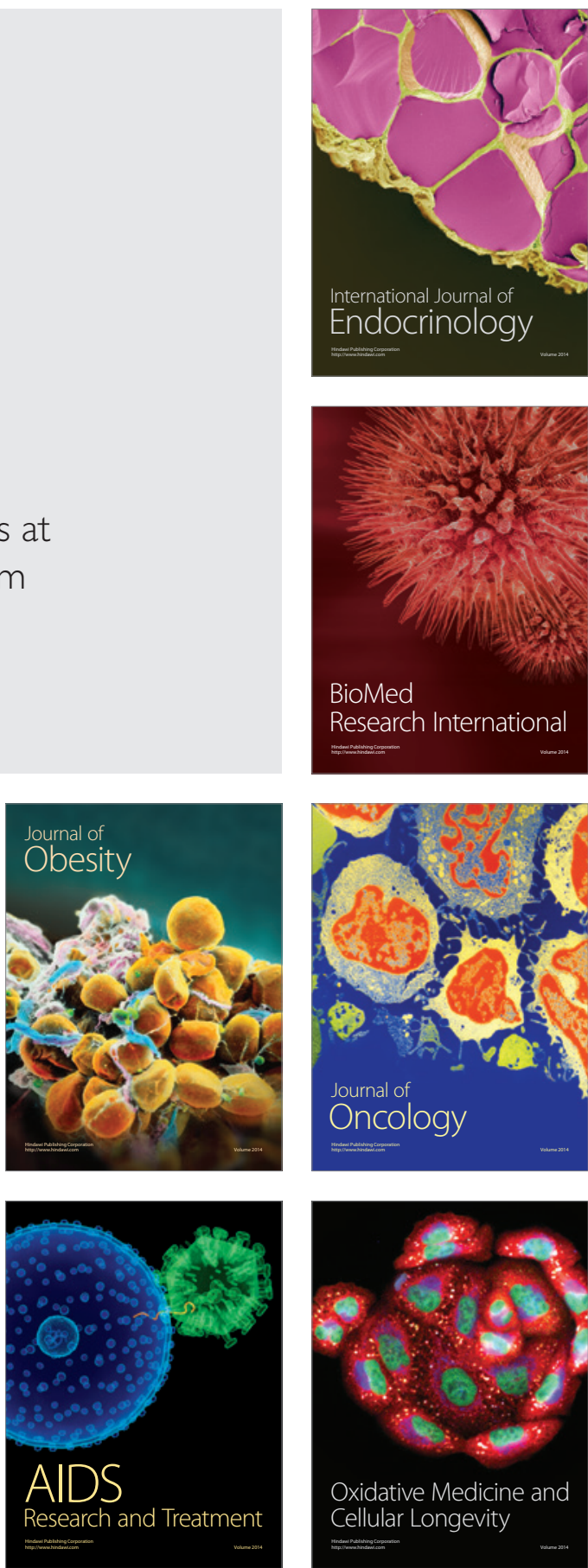